\begin{tabular}{|c|c|c|}
\hline Beitr. Ent. & Berlin & ISSN 0005-805X \\
\hline $48(1998) 2$ & S. $367-406$ & 05.10 .1998 \\
\hline
\end{tabular}

\title{
Studien zur Systematik und Faunistik der Gattung Tachypo- rus GRAVENHORST - Teill 7. Alte und neue Tachyporus aus dem Fernen Osten, Sachalin und Japan ${ }^{1}$
}

\section{(Coleoptera: Staphylinidae, Tachyporinae)}

Mit 21 Tabellen und 37 Textfiguren

\section{MICHAEL SCHÜLKE}

\section{Zusammenfassung}

Die Tachyporus-Arten Japans und Sachalins werden revidiert. Das Vorkommen von 16 Arten im Untersuchungsgebiet (Japan 11 Arten, Sachalin 7 Arten) kann nachgewiesen werden. Von den folgenden Arten werden Lectotypen designiert: Tachyporus celatus SHARP, 1874; Tachyporus oculatus SHARP, 1888 und Tachyporus suavis SHARP, 1888. Drei Arten aus Japan (celatoides sp. n. (Honshu), cephalotes sp. n. (Honshu) und japonicus sp. n. (Shikoku, Honshu)), zwei Arten von Sachalin (puetzi sp. n. und wrasei sp. n.) sowie zwei Arten aus dem Fernen Osten Rußlands (ussuriensis sp. n. (Mt. Olkhovaya) und zerchei sp. n. (Region Chabarovsk) werden beschrieben. Tachyporus manchuricus BERNHAUER, 1938 wird als Synonym zu Tachyporus terminalis SHARP, 1888 gestellt. Tachyporus klapperichi SCHÜLKE und Tachyporus abdominalis (FABRICIUS) werden als neu für die Fauna Japans gemeldet. Aedoeagi und Flügeldeckenbeborstung der behandelten Arten werden abgebildet, ein Schlüssel für die von Japan und Sachalin bekannten Arten der Gattung wird präsentiert. Die Verbreitung der Arten und ihre vermutliche Herkunft werden diskutiert.

\section{Summary}

The Tachyporus species of Japan and Sachalin are revised. 16 species are recorded from this region (Japan 11 species, Sachalin 7 species). Lectotypes are designated for the following species Tachyporus celatus SHARP, 1874; Tachyporus oculatus SHARP, 1888 and Tachyporus suavis SHARP, 1888. Three species from Japan (celatoides sp. n. (Honshu), cephalotes sp. n. (Honshu) and japonicus sp. n. (Shikoku and Honshu)), two species from Sakhalin (puetzi sp. n. and wrasei sp. n.) and two species from the Russian Far East (ussuriensis sp. n. (Mt. Olkhovaja) and zerchei sp. n. (Chabarovsky Kray)) are described. Tachyporus manchuricus BERNHAUER, 1939 is regarded as a synonym of Tachyporus terminalis SHARP, 1888. Tachyroprus klapperichi SCHÜLKE and Tachyporus abdominalis (FABRICIUS) are new records from Japan. Drawings of the aedeagi and elytral chaetotaxy of the species dealt with in the study are provided, a key of the Tachyporus species of Japan and Sakhalin is presented. The distribution of the species and their origin are discussed.

${ }^{1}$ Beiträge zur Kenntnis ostpaläarktischer Insekten (8)

28. Beitrag zur Kenntnis der Tachyporinen. 
Key words

Coleoptera, Staphylinidae, Tachyporinae, Tachyporus, Species novae, New Synonym, Lectotypes, Palaearctic, Russia, Siberia, Sachalin, Japan.

\section{Einleitung}

Aus verschiedenen europäischen und nordamerikanischen Sammlungen vorgelegtes Material der Gattung Tachyporus aus Japan zeigte, daß die auf dem Japanischen Archipel vorkommende Artenzahl wesentlich größer ist, als bisher bekannt war. Dies war nach Berücksichtigung der in jüngster Vergangenheit erfolgten Revision anderer Staphylinidengattungen (Stenus, Nazeris, Lobrathium, Protocypus, Siagonium, Carphacis und andere) zunächst nicht überraschend. Es zeigte sich aber bei der weiteren Bearbeitung, daß die wenigen bisher beschriebenen Arten zum Teil falsch gedeutet wurden. Meldungen westpaläarktischer Arten (atriceps STEPHENS, chrysomelinus (LINNÉ), pusillus GRAVENHORST) beruhen auf Falschmeldungen oder müssen zumindest als fraglich angesehen werden. Unsere gegenwärtigen Kenntnisse über die Tachyporus-Arten Japans müssen auch nach Vorlage der nachfolgenden Ergebnisse als dringend verbesserungsbedürftig eingeschätzt werden. Das zur Bearbeitung vorliegende Material erlaubt durch seine geringe Menge (nur 202 Exemplare) keine vollständige Revision der Japanischen TachyporusArten. Durch die Untersuchung des gesamten Typenmaterials bildet sie aber eine Basis, auf der sich weiter aufbauen läßt. Zeitgleich mit der Bearbeitung der japanischen Tachyporus wurde durch die Kollegen ANDREAS PÜTZ (Eisenhüttenstadt) und DAVID WRASE (Berlin) umfangreiches Tachyporus-Material von der Japan benachbarten Insel Sachalin vorgelegt, das die Einbeziehung in die vorliegende Bearbeitung erlaubt. Mit Tachyporus ussuriensis und T. zerchei werden hier außerdem zwei Arten der atriceps-Gruppe aus dem Fernen Osten Rußlands beschrieben, die schon anläßlich der Bearbeitung der westpaläarktischen Arten dieser Artengruppe (siehe Teil 5 dieser Reihe) aufgefunden wurden.

\section{Merkmale}

Meßwerte wurden mit Hilfe eines Okularmikrometers bei Vergrößerungen von 25x und 100x mit dem Binokular gewonnen.

Länge der Hautflügel: Die meisten im Untersuchungsgebiet vorkommenden Arten besitzen lange Hautflügel und sind vermutlich flugfähig. Einige Arten besitzen bis auf geringe Reste reduzierte Hautflügel. Sie besitzen aber meist noch einen Hautsaum am Hinterrand des Tergit VII, was auf ein geringes Alter der Hautflügelreduktion schließen läßt. Zumindest Tachyporus abdominalis (FABRICIUS) ist in der Ausbildung der Hautflügel deutlich dimorph.

Flügeldeckenbeborstung: Die Nomenklatur folgt der Flügeldeckenchaetotaxie nach CAMPBELL (1979) und SCHÜLKE (1991). Im Unterschied zu zahlreichen westpaläarktischen Tachyporus, bei denen die Flügeldeckenbeborstung besonders im Bereich der Humeral- und Sublateralbeborstung bis auf wenige Ausnahmen sehr stabil ist, kommen in der östlichen Paläarktis Arten mit teilweise sehr variabler Flügeldeckenbeborstung vor. In den zur Darstellung der Variabilität der Flügeldeckenchaetotaxie dienenden Tabellen bezeichnet " $n$ " die Anzahl der ausgewerteten Flügeldecken.

Fig. 1-8: Flügeldeckenbeborstung von Tachyporus: 1 oculatus SHARP; 2 japonicus $\mathrm{sp} . \mathrm{n} . ; 3$ orthogrammus SHARP; 4 cephalotes sp. $\mathrm{n}$.; 5 klapperichi SCHÜLKE (Japan); 6 celatus SHARP; 7 celatoides $\mathrm{sp} . \mathrm{n} . ; 8$ chrysomelinus (LINNÉ); Maßstab 0,5 mm. 

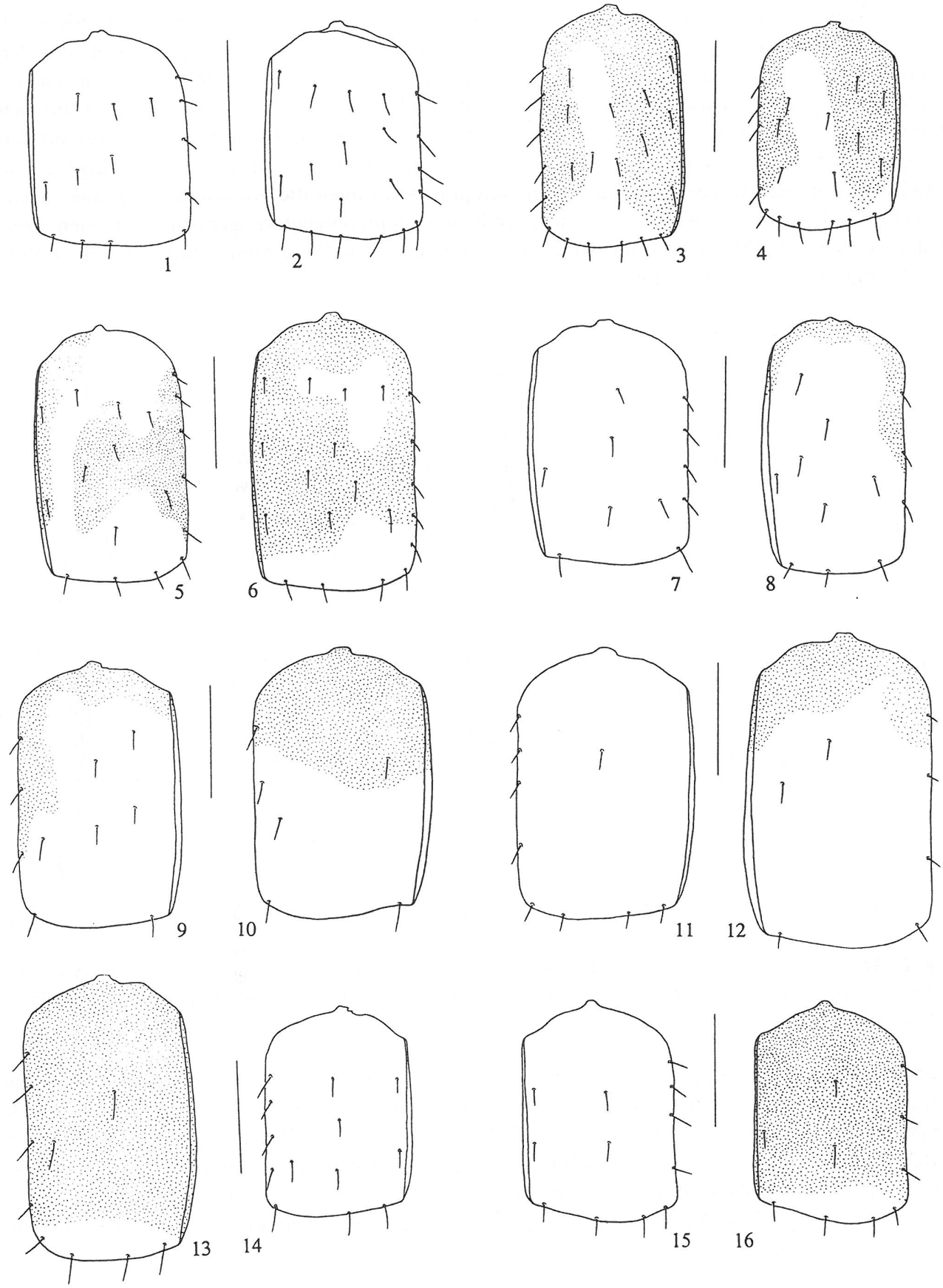

Fig. 9-16: Flügeldeckenbeborstung von Tachyporus: 9 wrasei sp. n.; 10 terminalis SHARP; 11 frontalis CAMERON; 12 puetzi sp. n.; 13 suavis SHARP; 14 abdominalis (FABRICIUS); 15 ussuriensis sp. n.; 16 zerchei sp. n.; Maßstab 0,5 mm. 
Mikroskulptur: Die Mikroskulptur bei Tachyporus-Arten besteht aus einer mikroskopisch feinen Struktur paralleler Linien oder sehr querer Maschen. Auf den Flügeldecken und den Hinterleibssegmenten kann die Mikroskulptur selten aus rhombischen Maschen bestehen. Die im Untersuchungsgebiet vorkommenden Arten besitzen alle eine deutliche Mikroskulptur auf den Hinterleibssegmenten und bis auf wenige Ausnahmen auch eine deutliche Mikroskulptur auf den Flügeldecken. Halsschild und Kopf sind nur bei wenigen Arten chagriniert. Im Text angegebene Meßwerte für die Maschenweite der Mikroskulptur bezeichnen die Anzahl der auf einer Meßstrecke (in Längsrichtung) von $10 \mu \mathrm{m}$ befindlichen, hintereinanderliegenden Querlinien bzw. Quermaschen. Die Mikroskulptur wurde mit Hilfe eines Oberflächenmikroskops bei einer Vergrößerung von 200x untersucht.

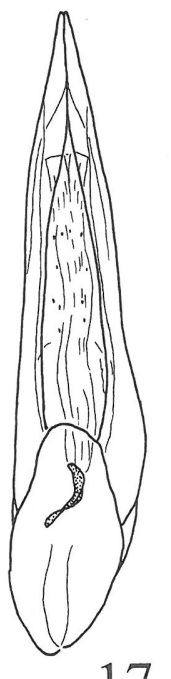

17

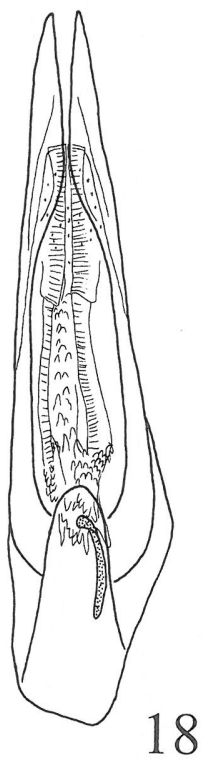

18
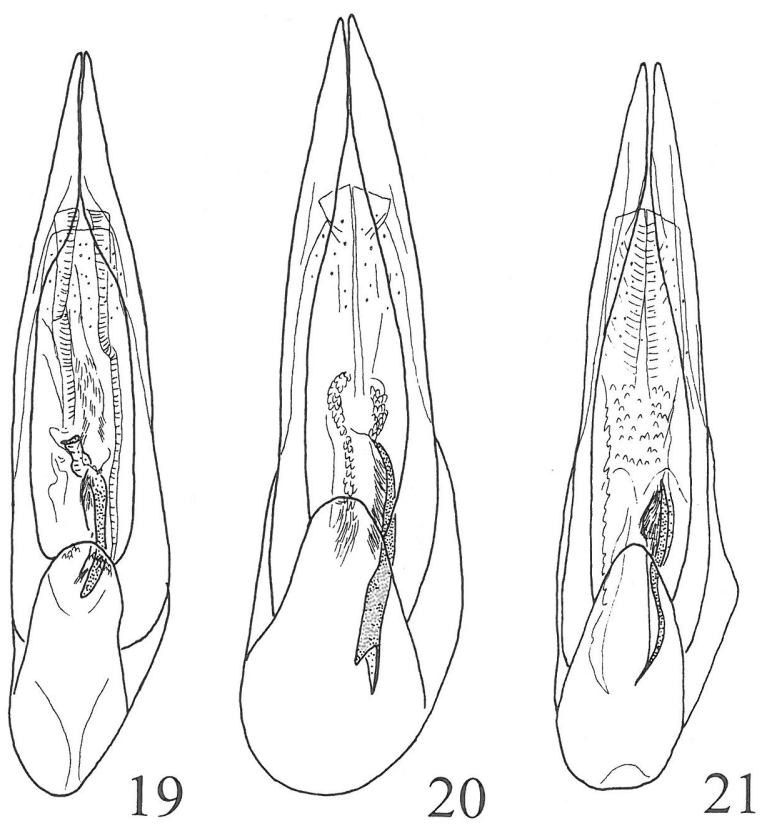

Fig. 17-21: Aedoeagi von Tachyporus: 17 oculatus SHARP, Lectotypus; 18 celatus SHARP, Lectotypus; 19 celatoides sp. n., Holotypus; 20 frontalis CAMERON, Holotypus; 21 suavis SHARP, Lectotypus; Maßstab $0,5 \mathrm{~mm}$.

Aedoeagus: Der Aedoeagus von Tachyporus besitzt zwei symmetrische, wenig sklerotisierte Parameren, die dem Medianlobus dicht anliegen. Im Inneren des Medianlobus befinden sich zwei lange, nicht mit stärker sklerotisierten Teilen versehene Ausstülpschläuche, bei den meisten Arten im zentralen Teil des Medianlobus schwach sklerotisierte Börstchenfelder oder Ausstülpkörper. Die meisten Arten besitzen im Basalteil des Aedoeagus eine mit den Enden der paarigen Ausstülpschläuche verbundene, teilweise sklerotisierte Struktur oder stark sklerotisierte und arttypisch geformte Sklerite.

Fig. 22-26: Aedoeagi von Tachyporus: 22 japonicus sp. n., Paratypus, Ishizuchi Mtns. N.P.; 23 orthogrammus SHARP, Ishizuchi Mtns. N.P.; 24 cephalotes sp. n., Paratypus, Okayama; 25 klapperichi SCHÜLKE, Osaka; 26 celatoides sp. n., Paratypus, Nara, Riv. Kizu; Maßstab 0,5 mm. 

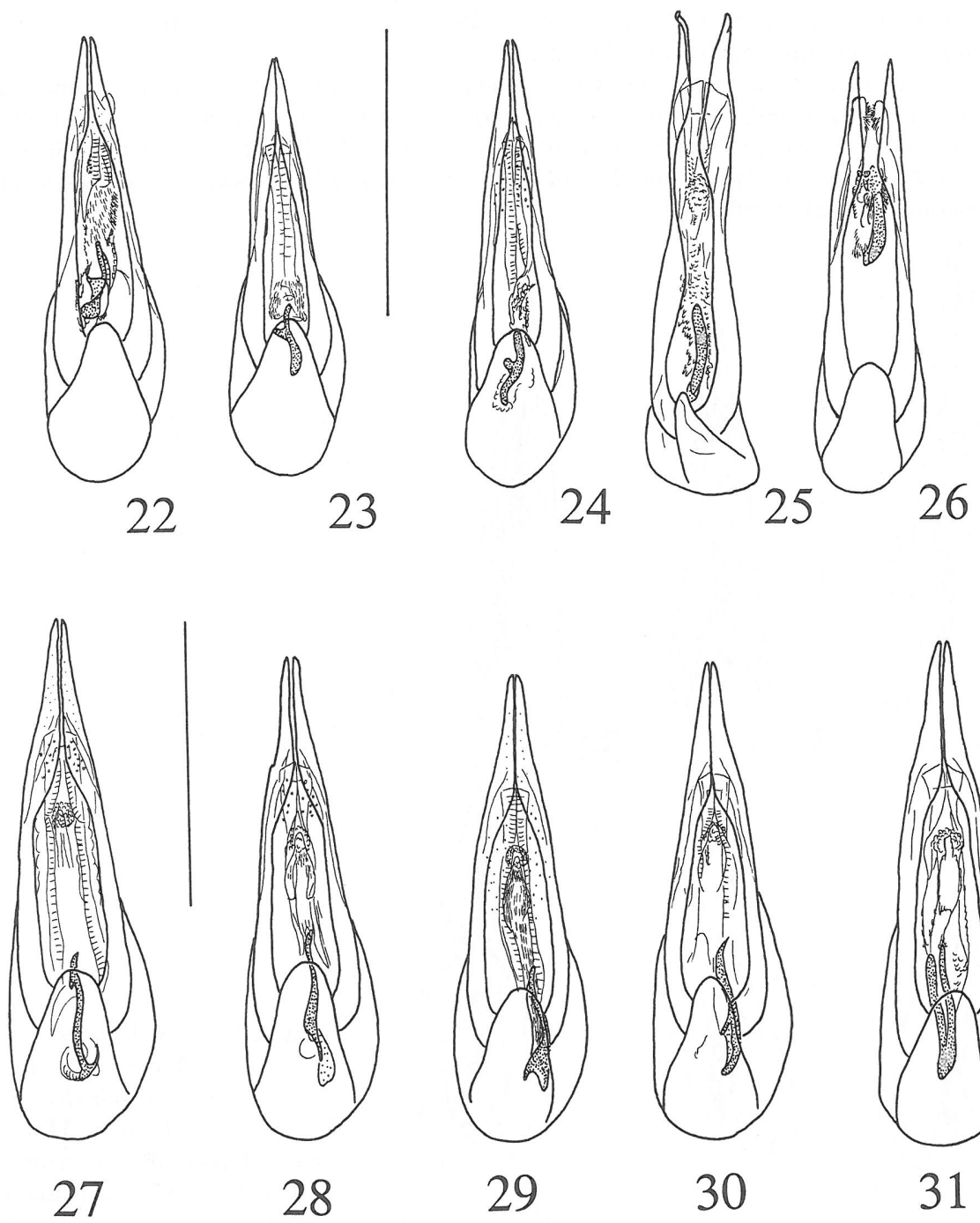
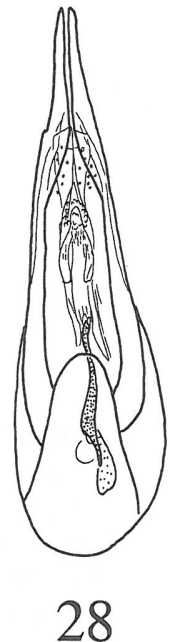

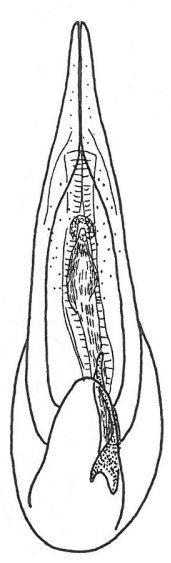

29

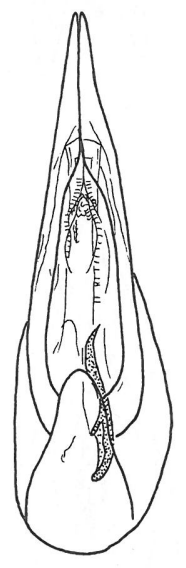

30

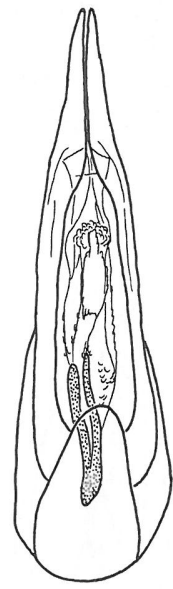

31

Fig. 27-31: Aedoeagi von Tachyporus: 27 chrysomelinus (LINNÈ), Sachalin, Korsakov distr.; 28 wrasei sp. n., Holotypus, Sachalin, Tymovskiy distr.; 29 wrasei sp. n., Paratypus, Tymovskiy distr.; 30 wrasei sp. n., Paratypus, Tymovskiy distr.; 31 terminalis SHARP, Sachalin, Kirillovo; Maßstab 0,5 mm.

\section{Danksagung}

Für die Ausleihe von Typen und weiterem Material, dem Überlassen von Belegen für meine Vergleichssammlung gilt den folgenden Kollegen mein herzlicher Dank:

The Natural History Museum, London, E. DeBoISE \& M. BRENDELL (BMNH);

Field Museum of Natural History, Chicago, A.F. NEWTON JR. \& M. THAYER (FMNH);

Museum d'Histoire naturelle de Geneve, I. LÖBL, G. CUCCODORO (MHNG);

Naturhistorisches Museum Wien, H. SchÖNMANN, H. SCHILLHAMMER (NHMW);

Deutsches Entomologisches Institut, Eberswalde, Dr. L. ZERCHE (DEI); 
Museum für Naturkunde der Humboldt-Universität zu Berlin, Dr. M. UHLIG (MNHUB);

Herrn ANDREAS PÜTZ, Eisenhüttenstadt (cPÜTZ).

Besonderer Dank gilt auch hier wieder meinem Freund DAVID WRASE (Berlin), der die gesamte Staphylinidenausbeute der Sachalin-Exkursion für meine Vergleichssammlung (im weiteren mit "cSCHÜ" gekennzeichnet) zur Verfügung stellte. Für wertvolle Diskussionen und Unterstützung bei der Suche nach Literatur zur Zoogeographie Japans und Sachalins bin ich L. ZERCHE (Eberswalde), M. UHLIG und B. JAEGER (Berlin) zu Dank verpflichtet.
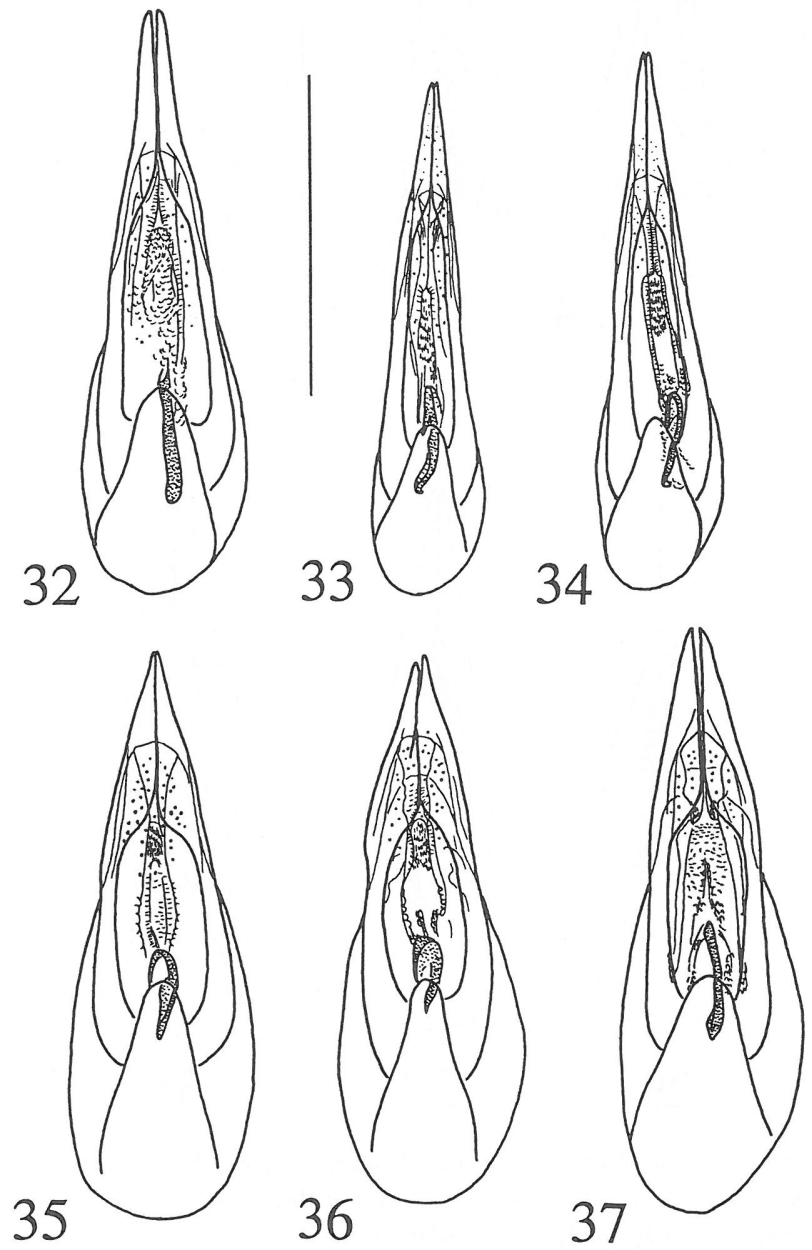

Fig. 32-37: Aedoeagus von $\mathrm{Ta}$ chyporus: 32 puetzi sp. n., Holotypus; 33 abdominalis (FABRICIUS), Nogi, Tochigi; 34 abdominalis (FABRICIUS), Sachalin, Korsakov distr.; 35 ussuriensis $\mathrm{sp}$. n., Paratypus, Mt. Olkhovaja; 36 ussuriensis sp. n., Holotypus; 37 zerchei sp. n., Holotypus; Maßstab $0,5 \mathrm{~mm}$.

\section{Revision der von Japan und Sachalin vorliegenden Arten}

\section{Tachyporus oculatus SHARP, 1888}

\section{Typenmaterial}

Lectotypus: ठิ, Tachyporus oculatus Type D.S., Japan, Lewis [auf dem Aufklebeplättchen] / Type [rund, roter Rand] / Japan, G. Lewis / Sharp Coll., 1905-313 / Lectotypus, Tachyporus oculatus Sharp, 1888, des. M. Schülke 1995 (BMNH). Hiermit designiert! 
Paralectotypen: \&, Tachyporus oculatus D.S., Japan, Lewis [auf dem Aufklebeplättchen] / Japan, G. Lewis / Sharp Coll., 1905-313 / Paralectotypus, Tachyporus oculatus Sharp, 1888, des. M. Schülke 1995 / 2 Ex. (BMNH).

Tachyporus oculatus SHARP wurde nach sechs Exemplaren beschrieben. Aus dem BMNH lagen drei Syntypen vor, eine weitere befindet sich in der Sammlung des FMNH, sie wurde nicht untersucht. Da unter dem Namen Tachyporus oculatus bisher mehrere Arten vermengt wurden und die Art nach mehreren Syntypen beschrieben wurde, die nicht alle zur Untersuchung vorlagen, war die Festlegung eines Lectotypus zwingend erforderlich. Lectotypus und Paralectotypen sind auf Kartonplättchen geklebt und gut erhalten, Paralectotypus 2 ist auf den Rücken geklebt, beim Lectotypus fehlen die Tarsen des linken Vorderbeins und das rechte Hinterbein, beim Paralectotypus 1 das linke Hinterbein und beim Paralectotypus 2 Fühler links ab Glied 2, Tarsenglied 5 des linken Mittelbeins, alle Tarsen des rechten Mittelbeins, das gesamte rechte Hinterbein und die Tarsen des linken Hinterbeins ab Glied 3 (Bein neben das Tier geklebt).

\section{Weiteres Material}

Ocyama, Japan, Sauter, 1 Ex. (NHMW).

\section{Ergänzungen zur Beschreibung}

Meßwerte des Lectotypus (in mm): Kopfbreite: 0,73; Halsschildbreite: 1,07; Halsschildlänge: 0,69 ; Flügeldeckennahtlänge: 0,68 ; Flügeldeckenschulterlänge: 0,81 ; Flügeldeckenbreite: 1,03 ; Vorderkörperlänge: 1,76; Gesamtlänge: 3,47; Aedoeaguslänge: 0,73.

Flügeldeckenbeborstung des Lectotypus (links/rechts): Humeral: 1/1; Sublateral: 0/0; Diskal (innen): 2/2; Diskal (Mitte): 2/2; Diskal (außen): 0/0; Sutural: 2/2; Apikal: 4?/5; Lateral: 4/4. Flügeldecken (Fig. 1) kurz, etwas schmaler als der Halsschild, Fühler gestreckt, Glied 9 u. 10 deutlich länger als breit, Tergit VII ohne Hautsaum am Hinterrand.

\begin{tabular}{|l|c|c|c|c|c|c|}
\hline $\mathrm{n}=4$ & 0 Borsten & 1 Borste & 2 Borsten & 3 Borsten & 4 Borsten & 5 Borsten \\
\hline Humeral & 0 & 100 & 0 & 0 & 0 & 0 \\
\hline Sublateral & 100 & 0 & 0 & 0 & 0 & 0 \\
\hline Diskal (innen) & 0 & 0 & 100 & 0 & 0 & 0 \\
\hline Diskal (Mitte) & 0 & 0 & 100 & 0 & 0 & 0 \\
\hline Diskal (außen) & 100 & 0 & 0 & 0 & 0 & 0 \\
\hline Sutural & 0 & 50 & 50 & 0 & 0 & 0 \\
\hline Apikal & 0 & 0 & 0 & 0 & 50 & 50 \\
\hline Lateral & 0 & 0 & 0 & 0 & 75 & 25 \\
\hline
\end{tabular}

Tab. 1: Variabilität der Flügeldeckenbeborstung von Tachyporus oculatus SHARP.

Mikroskulptur: Kopf auf der Stirn mit deutlichen kurzen Maschen (1 Masche auf 10-15 $\mu \mathrm{m}$ ), am Hinterrand mit engeren, deutlich queren Maschen (1 Masche/10 $\mu \mathrm{m})$, Halsschild und Flügeldecken mit deutlicher Mikroskulptur von 2-3 Maschen $/ 10 \mu \mathrm{m}$, Hinterleib mit engem Chagrin von 4-5 Maschen $/ 10 \mu \mathrm{m}$. 
Aedoeagus: Der Aedoeagus von oculatus (Fig. 17) ist schlank und besitzt keine deutlich sichtbaren Innenstrukturen im Zentralbereich des Medianlobus und ein kleines Basalsklerit.

Verbreitung: Bisher nur aus Japan (Honshu) bekannt (Miyanoshita und Hakone).

Tachyporus oculatus SHARP ist eine valide Art aus der Tachyporus atriceps-Gruppe, vom ähnlich gefärbten $T$. ruficollis GRAVENHORST ist sie durch Mikroskulptur und Flügeldeckenbeborstung einfach zu unterscheiden. Die Art wurde bisher mit dem neu beschriebenen Tachyporus japonicus sp. n. konfundiert, von dem sie sich ebenfalls durch die Flügeldeckenbeborstung deutlich unterscheidet.

\section{Tachyporus japonicus sp. $\mathrm{n}$.}

\section{Typenmaterial}

Holotypus: Japan, Honshu, B.M. 1980-492, P.M. Hammond, 8m, N Kyoto, Seryo Toge, 6.8.80, leaf litter (BMNH).

Paratypen: gleiche Daten wie der Holotypus, 6 Ex. (BMNH, cSCHÜ); Japan Honshu, Kyoto Palace Gdns., 7.-20.8.80, 1 Ex. P.M. Hammond (BMNH); Japan, Shikoku, Ishizuchi Mtn. NP, Tsuchigoya, 1400 m, 11.-18.08.1980, Berl., litter Fagus-Abies for., logs/stumps/moss + fungi, S + J. Peck, 7 Ex. (FMNH, cSCHÜ); Japan; Ehime; via Mt. Ishizuchi,; 1350m; 13; 08; 1980; 1 Ex; Besuchet; (MHNG); Japan, Ehime, Ishizuchi N.P., Mt. Ishizuchi, 13.08.1980, 10 Ex., Besuchet, (MHNG, cSCHÜ); Japan, Ehime, Ishizuchi N.P., Mt. Ishizuchi, $1550 \mathrm{~m}$, Löbl, 13.8.1980, 1 Ex. (MHNG); Japon, Ehime, via Mt. Ishizuchi, 1350 m, Löbl, 13.8.1980, 1 Ex. (MHNG).

\section{Beschreibung und Differentialdiagnose}

Meßwerte des Holotypus (in mm): Kopfbreite: 0,67; Halsschildbreite: 0,95; Halsschildlänge: 0,62; Flügeldeckennahtlänge: 0,55 ; Flügeldeckenschulterlänge: 0,72 ; Flügeldeckenbreite: 1,10 ; Vorderkörperlänge: 1,78; Gesamtlänge: 3,45; Aedoeaguslänge: 0,67.

Längenverhältnisse der Fühlerglieder 1-11: 7:5,5:6:5,5:6:5,5:5,5:5,5:5:5,25:9.

Verhältnis Länge/Breite von Fühlerglied 5: 1,85; 7: 1,38; 9: 1,25; 10: 1,31 und 11: 1,89.

Flügeldeckenbeborstung des Holotypus (links/rechts): Humeral: 0/0; Sublateral: 2/2; Diskal (innen): 2/2; Diskal (Mitte): 2/2; Diskal (außen): 0/0; Sutural: 2/3; Apikal: 5/5; Lateral: 4/4.

Färbung: Kopf schwarz, Halsschild schwarzbraun, Vorder- und Hinterrand schmal, die Seitenränder breiter gelb gerandet, Schildchen schwarz, Flügeldecken pechbraun bis schwarz mit schmalem gelbem Hinterrand, Abdomen schwarz mit undeutlich aufgehellten Hinterrändern der Segmente. Beine gelb, Labrum braun, Taster gelb, auch die beiden letzten Glieder der Kiefertaster kaum dunkler, Fühlerbasis gelb, die Glieder ab 5 etwas bräunlich angedunkelt.

Kopf breit (Kopfbreite : Halsschildlänge beim Holotypus 1,08), glänzend. Augen deutlich vorgewölbt. Oberfläche des Kopfes mit mikroskopisch feiner weitläufiger Punktur ohne sichtbare Behaarung. Fühler gestreckt, die vorletzten Glieder deutlich länger als breit.

Halsschild quer (Breite zu Länge 1,54 beim Holotypus), Vorderrand breit, die Seitenränder schmal, der Hinterrand nur in den Außenecken fein gerandet. Vorderecken nach unten umgebogen, abgerundet rechtwinklig, Hinterecken völlig verrundet. An Vorder-, Seiten- und Hinterrand befinden sich wie bei allen anderen Arten der Gattung je vier kräftige Borstenpunkte, in denen kräftige schwarze Tastborsten inserieren. Die Oberfläche des Halsschildes mit mikroskopisch feiner weitläufiger Punktur. Schildchen abgerundet dreieckig, vollständig unter dem Halsschild verborgen.

Flügeldecken (Fig. 2) kurz, zusammen wesentlich breiter als lang (Schulterlänge : Breite beim Holotypus 0,65), ihre Nahtlänge kürzer als die Halsschildlänge (Holotypus 0,89). Flügeldecken 
mit feiner Grundpunktur (Punktabstand ca. $40 \mu \mathrm{m}$ ), in der eine helle und feine, anliegende Grundbehaarung inseriert (Länge der Behaarung ca. $60 \mu \mathrm{m}$ ). Neben der Grundpunktur befinden sich auf den Flügeldecken meist zwei Sublateralborstenpunkte, meist zwei (selten drei) Reihen Diskalborstenpunkte, zwei bis drei Suturalborstenpunkte, meist vier Lateral- und fünf Apikalborstenpunkte. Humeralborstenpunkte sind nur auf der Hälfte der ausgewerteten Flügeldecken vorhanden. In den Borstenpunkten inserieren kräftige abstehende Tastborsten von bis zu $180 \mu \mathrm{m}$ Länge. Die Variabilität der Flügeldeckenbeborstung (siehe Tabelle) übersteigt das gewöhnlich bei Tachyporus übliche Maß. Dies gilt besonders für die Variabilität des Vorkommens von Humeralborstenpunkten. Eine Beziehung der Flügeldeckenbeborstung zur geographischen Verbreitung auf den japanischen Hauptinseln läßt sich aus dem vorliegenden Material nicht ableiten. Hautflügel rudimentär, nur ein Drittel der Flügeldeckenlänge erreichend.

\begin{tabular}{|l|c|r|r|r|c|c|c|}
\hline $\mathrm{n}=23$ & 0 Borsten & 1 Borste & 2 Borsten & 3 Borsten & 4 Borsten & 5 Borsten & 6 Borsten \\
\hline Humeral & 50 & 50 & 0 & 0 & 0 & 0 & 0 \\
\hline Sublateral & 0 & 9 & 86 & 5 & 0 & 0 & 0 \\
\hline Diskal (innen) & 0 & 0 & 95 & 5 & 0 & 0 & 0 \\
\hline Diskal (Mitte) & 0 & 9 & 82 & 9 & 0 & 0 & 0 \\
\hline Diskal (außen) & 86 & 14 & 0 & 0 & 0 & 0 & 0 \\
\hline Sutural & 0 & 0 & 52 & 48 & 0 & 0 & 0 \\
\hline Apikal & 0 & 0 & 0 & 0 & 5 & 86 & 9 \\
\hline Lateral & 0 & 0 & 0 & 5 & 85 & 10 & 0 \\
\hline
\end{tabular}

Tab. 2: Variabilität der Flügeldeckenbeborstung von Tachyporus japonicus sp. n.

Hinterleib wie bei allen Arten der Gattung nach hinten konisch zugespitzt. Die Oberfläche der Segmente in ähnlicher Dichte und Stärke wie die Flügeldecken punktiert und mit feiner Grundbehaarung versehen. Die einzelnen Segmente an den Seiten mit langen schwarzen Tastborsten, die Spitze des Hinterleibes mit zahlreichen kräftigen und langen schwarzen Tastborsten von bis zu 0,40 mm Länge. Tergit VII am Hinterrand ohne Hautsaum. Beine wie bei den anderen Arten der Gattung.

Mikroskulptur: Kopf kräftig quermaschig um den Scheitel herum chagriniert (ca. 2 Maschen/ $10 \mu \mathrm{m}$ ), Halsschild und Flügeldecken deutlich eng querlinig chagriniert (3-4 Maschen/10 $\mu \mathrm{m}$ ), Hinterleib noch enger als die Flügeldecken quermaschig chagriniert (ca. 5 Maschen $/ 10 \mu \mathrm{m}$ ).

Männchen: Vordertarsenglieder 1-3 deutlich erweitert, Mitteltarsen einfach, Sternit VIII am Hinterrand abgerundet dreieckig ausgeschnitten, Aedoeagus (Fig. 22) schlank mit einem zentralen Feld feiner Börstchen und kräftigem Basalsklerit.

Weibchen: Vordertarsen kaum erweitert, Tergit VIII am Hinterrand mit drei tiefen Einschnitten, vierzipfelig.

Derivatio Nominis: Der Name japonicus leitet sich von der Verbreitung der Art auf dem Japanischen Archipel ab. 
Tachyporus japonicus gehört zur atriceps-Gruppe und ist mit oculatus nahe verwandt. Beide Arten unterscheiden sich hauptsächlich durch die fehlende Sublateral-Beborstung der Flügeldecken bei oculatus, die etwas engere Mikroskulptur auf Kopf, Halsschild und Flügeldecken von japonicus und den Bau des Aedoeagus, besonders durch die Form des Sklerits im Basalteil des Aedoeagus. Die beiden anderen großköpfigen Arten unterscheiden sich von japonicus außer durch die Flügeldeckenbeborstung und den Bau des Aedoeagus auch durch die größere Länge und teilweise gelbe Färbung der Flügeldecken (orthogrammus SHARP und cephalotes sp. n.) bzw. durch das Vorhandensein eines Hautsaums am Tergit VII (orthogrammus SHARP).

\section{Tachyporus orthogrammus SHARP, 1888}

\section{Typenmaterial}

Holotypus- $\uparrow$ : Tachyporus orthogrammus Type D.S., Kiga, Japan, Lewis [auf dem Aufklebeplättchen] / Type [rund, roter Rand] / Kiga / Japan, G. Lewis, 1910-320 / Holotypus- 9 , Tachyporus orthogrammus Sharp, 1888, det. M. Schülke 1995 (BMNH).

Tachyporus orthogrammus wurde nach einem Einzelstück beschrieben. Der Holotypus ist schräg auf ein großes Kartonplättchen geklebt, Halsschild mit Beschädigung auf der Scheibe, am Fühler links fehlt Glied 11, rechts die Glieder 8-11 neben das Tier auf das Plättchen geklebt.

\section{Weiteres Material}

Japan, Shikoku, Ishizuchi Mtn. NP, Tsuchigoya, 1400 m, 11.-18.8.1980, Berl. Betula-Fagus log, stump, moss, litter + fungi, S. \& J. Peck, 4 Ex. (FMNH, cSCHÜ); Japan, Mt. Tahao, leg. Yoshida Wada, 22.7.53, 1 Ex. (NHMW).

\section{Ergänzungen zur Beschreibung}

Meßwerte des Holotypus (in mm): Kopfbreite: 0,70; Halsschildbreite: 1,02; Halsschildlänge: 0,63 ; Flügeldeckennahtlänge: 0,80 ; Flügeldeckenschulterlänge: 0,87 ; Flügeldeckenbreite: 1,02; Vorderkörperlänge: 1,60; Gesamtlänge: 2,77.

\begin{tabular}{|l|c|c|c|c|c|c|c|}
\hline $\mathrm{n}=10$ & 0 Borsten & 1 Borste & 2 Borsten & 3 Borsten & 4 Borsten & 5 Borsten & 6 Borsten \\
\hline Humeral & 0 & 100 & 0 & 0 & 0 & 0 & 0 \\
\hline Sublateral & 0 & 0 & 83 & 17 & 0 & 0 & 0 \\
\hline Diskal (innen) & 0 & 0 & 50 & 50 & 0 & 0 & 0 \\
\hline Diskal (Mitte) & 0 & 0 & 12,5 & 75 & 12,5 & 0 & 0 \\
\hline Diskal (außen) & 0 & 71 & 29 & 0 & 0 & 0 & 0 \\
\hline Sutural & 0 & 0 & 12,5 & 75 & 12,5 & 0 & 0 \\
\hline Apikal & 0 & 0 & 0 & 0 & 0 & 17 & 93 \\
\hline Lateral & 0 & 0 & 0 & 0 & 20 & 60 & 20 \\
\hline
\end{tabular}

Tab. 3: Variabilität der Flügeldeckenbeborstung von Tachyporus orthogrammus SHARP. 
Flügeldeckenbeborstung des Holotypus (links/rechts): Humeral: 1/1; Sublateral: 3/2; Diskal (innen): 3/3; Diskal (Mitte): 3/3; Diskal (außen): 2/2; Sutural: 3/4; Apikal: 5?/6; Lateral: ?/6. Kopf und Halsschild schwarz, letzterer mit schmalem hellen Rand, Flügeldecken (Fig. 3) schwarz mit breitem gelben Hinterrand und einem vom Hinterrand bis zur Schulter reichenden gelben Längsband, Epipleuren der Flügeldecken gelbbraun. Hinterleib schwarzbraun, die Hinterränder der Segmente kaum aufgehellt. Beine, Fühler und Mundteile gelb. Tergit VII mit deutlichem Hautsaum am Hinterrand. Mikroskulptur: Kopf mit weitläufiger, kurzmaschiger Mikroskulptur (etwa eine Masche/15 $\mu \mathrm{m}$ ), Halsschild viel enger, quermaschig chagriniert (2 Maschen/10 $\mu \mathrm{m}$ ), Flügeldecken und Hinterleib noch enger (3 Maschen/10 $\mu \mathrm{m}$ ) querwellig chagriniert.

Tachyporus orthogrammus ist eine Art aus der atriceps-Gruppe aus der Verwandtschaft von $T$. ruficollis GRAVENHORST. Die Art wurde ebenfalls mit einer bisher unbeschriebenen Art konfundiert (Tachyporus cephalotes sp. $\mathrm{n}$.).

Männchen: Aedoeagus (Fig. 23) klein und schlank mit deutlichem Basalsklerit.

\section{Tachyporus cephalotes sp. n.}

\section{Typenmaterial}

Holotypus: Okayama, Japan, Sauter (NHMW)

Paratypen: gleiche Daten wie beim Holotypus, 3 Ex. (NHMW, cSCHÜ); Japan, Gifu, 8km SE Osaka, 22a, 750m, 01.08.1980, 2 Ex, Besuchet (MHNG, cSCHÜ); Japan, Yamanaka, leg. Ueno, 26.09.1950, 2 Ex. (NHMW, cSCHÜ).

\section{Beschreibung und Differentialdiagnose}

Meßwerte des Holotypus (in mm): Kopfbreite: 0,68; Halsschildbreite: 1,00; Halsschildlänge: 0,63 ; Flügeldeckennahtlänge: 0,57 ; Flügeldeckenschulterlänge: 0,78 ; Flügeldeckenbreite: 0,97 ; Vorderkörperlänge: 1,48; Gesamtlänge: 2,31; Aedoeaguslänge (Paratypus): 0,82.

Längenverhältnisse der Fühlerglieder 1-11: 8:5,5:6:6:6:5,75:5,75:5,75:5,5:5,5:9,25.

Verhältnis Länge/Breite von Fühlerglied 5: 2,00; $7: 1,64 ; 9: 1,37 ; 10: 1,22$ und 11: $1,85$.

Flügeldeckenbeborstung des Holotypus (links/rechts): Humeral: 0/1; Sublateral: 2/2; Diskal (innen): 3/3; Diskal (Mitte): 2/2; Diskal (außen): 0/1; Sutural: 3/3; Apikal: 6/6; Lateral: 4/3.

Färbung: Kopf schwarz, Halsschild variabel gefärbt, gelb mit breiter brauner Diskalmakel bis schwarzbraun mit schmalem gelbem Vorderrand, etwas breiterem Hinterrand und breiten gelben Seitenrändern, Schildchen braun, Flügeldecken dunkelbraun bis schwarz mit undeutlich aufgehellter Naht, hellem Hinterrand und je einer von der Schulter ausgehenden gelben Längsbinde, Abdomen dunkelbraun bis schwarz mit aufgehellten Hinterrändern der Segmente III - VII, ab Segment VIII ganz dunkel, Beine gelb, Labrum dunkelbraun mit hellen Seiten- und Vorderrand, Taster gelb, Fühler an der Basis hellgelb, zur Spitze kaum dunkler.

Kopf breit, die Kopfbreite etwa der Halsschildlänge entsprechend (beim Holotypus 1,08), die Augen deutlich vorgewölbt. Oberfläche etwas matt, sehr fein und weitläufig mit einer Mikropunktur versehen, eine darin inserierende Behaarung ist nicht feststellbar. Fühler gestreckt, ihre vorletzten Glieder deutlich länger als breit. Halsschild quer (Breite : Länge 1,59), Vorderrand breit, die Seitenränder deutlich, der Hinterrand außen fein gerandet. An Vorder-, Seiten- und Hinterrand befinden sich jeweils die gattungstypischen vier Borstenpunkte mit kräftigen dunklen Tastborsten. Oberfläche des Halsschildes glänzend, undeutlicher und weitläufiger als der Kopf mit einer Mikropunktur versehen. Vorderecken des Halsschildes nach vorn umgebogen, rechtwinklig kurz abgerundet, Hinterecken völlig abgerundet. Schildchen abgerundet dreieckig, vollständig unter dem Halschild verborgen. 
Flügeldecken (Fig. 4) kurz, deutlich breiter als lang (Schulterlänge : Breite 0,80), ihre Nahtlänge kleiner als die Halsschildlänge $(0,90)$. Flügeldecken mit feiner, etwas ungleichmäßiger Grundpunktur (Punktabstand ca. $50 \mu \mathrm{m}$ ), in der eine helle anliegende Grundbehaarung inseriert (Länge der Behaarung ca. $70 \mu \mathrm{m}$ ). Neben der Grundpunktur finden sich auf den Flügeldecken meist ein Humeralborstenpunkt, ein bis zwei Sublateralborstenpunkte, zwei Reihen von Diskalborstenpunkten, eine Suturalborstenpunktreihe, 5 bis 6 Apikal- und 4 Lateralborstenpunkte. In den Borstenpunkten inserieren kräftige abstehende Borsten von bis zu $180 \mu \mathrm{m}$ Länge. Variabilität der Flügeldeckenbeborstung siehe Tabelle. Hautflügel reduziert, viel kürzer als die Flügeldecken.

\begin{tabular}{|l|c|c|c|c|c|c|c|}
\hline $\mathrm{n}=8$ & 0 Borsten & 1 Borste & 2 Borsten & 3 Borsten & 4 Borsten & 5 Borsten & 6 Borsten \\
\hline Humeral & 17 & 83 & 0 & 0 & 0 & 0 & 0 \\
\hline Sublateral & 0 & 33 & 67 & 0 & 0 & 0 & 0 \\
\hline Diskal (innen) & 17 & 17 & 33 & 33 & 0 & 0 & 0 \\
\hline Diskal (Mitte) & 0 & 0 & 83 & 17 & 0 & 0 & 0 \\
\hline Diskal (außen) & 83 & 17 & 0 & 0 & 0 & 0 & 0 \\
\hline Sutural & 0 & 17 & 33 & 50 & 0 & 0 & 0 \\
\hline Apikal & 0 & 0 & 0 & 0 & 0 & 20 & 80 \\
\hline Lateral & 0 & 0 & 0 & 12 & 88 & 0 & 0 \\
\hline
\end{tabular}

Tab. 4: Variabilität der Flügeldeckenbeborstung von Tachyporus cephalotes sp. n.

Hinterleib wie bei allen Arten der Gattung nach hinten konisch zugespitzt, die Oberfläche der Segmente in ähnlicher Dichte und Stärke wie die Flügeldecken punktiert und anliegend fein behaart. Segmente III bis VII an den Seiten mit langen Tastborsten, die Segmente VIII bis X mit zahlreichen Tastborsten von bis zu 0,4 mm Länge. Tergit VII ohne Hautsaum.

Beine wie bei den anderen Arten der Gattung gebildet.

Mikroskulptur: Kopf mit kräftiger quermaschiger Mikroskulptur, die um den Scheitel herum angeordnet ist (Maschenweite ca. 2 Maschen/10 $\mu \mathrm{m}$ ), Halsschild und Flügeldecken viel feiner und enger (3-4 Maschen/10 $\mu \mathrm{m})$ querlinig chagriniert, Hinterleib mit feiner und enger querliniger Chagrinierung (ca. 5 Maschen/10 $\mu \mathrm{m}$ ).

Männchen: Vordertarsenglieder 1 bis 3 erweitert, Mitteltarsen einfach, Sternit VIII am Hinterrand mit flachem Mitteleinschnitt, Aedoeagus (Fig. 24) schlank, ohne deutliche Zentralstrukturen, mit kräftigem Sklerit im Basalteil.

Weibchen: Vordertarsen nicht erweitert, Tergit VIII am Hinterrand mit drei Einschnitten, vierzipfelig.

Derivatio Nominis: Der Artname weist auf den großen und breiten Kopf der Art hin.

Differentialdiagnose: Tachyporus cephalotes ist mit Tachyporus orthogrammus SHARP nahe verwandt und gehört wie dieser zur atriceps-Gruppe. Beide Arten unterscheiden sich durch die bei cephalotes viel kürzeren Flügeldecken mit aus drei Diskalreihen bestehender Beborstung und das Vorhandensein eines Hautsaumes am Hinterrand von Tergit VII bei orthogrammus. 


\section{Tachyporus klapperichi SCHÜLKE, 1995}

\section{Material}

Mt. Myoken, Osaka, Japan, 25.6.1993, N. Ito (DEI); Mt. Ohyama, Kanagawa, Japan, 4.6. 1994, N. Ito, 1 Ex. (cSCHÜ); Japan, Honshu Isl., SE slope of Mt. Fuji, 11.6.1955, leg. D. Lowrie, 1 Ex. (FMNH).

\section{Beschreibung der japanischen Exemplare}

Meßwerte (ð์ von Osaka): Kopfbreite: 0,72; Halsschildbreite: 1,14; Halsschildlänge: 0,79; Flügeldeckennahtlänge: 0,83 ; Flügeldeckenschulterlänge: 1,12; Flügeldeckenbreite: 1,10; Vorderkörperlänge: 2,22; Gesamtlänge: 4,74; Aedoeaguslänge: 0,82.

Längenverhältnisse der Fühlerglieder 1-11: 9:5:6:6:6:5,5:5,5:5:5:5:8,5.

Verhältnis Länge/Breite von Fühlerglied 5: 2,00; 7: 1,57; 9: 1,25; 10: 1,05 und 11: 1,70.

Färbung: Kopf schwarz, Halsschild dunkelbraun bis schwarz mit breitem gelben Seiten- und Hinterrand, der Vorderrand nur schmal gelb, Schildchen schwarz, Flügeldecken dunkelbraun bis schwarz mit gelben Schultern und breit gelbem Hinterrand. Von den Schultern zu den Nahtwinkeln der Flügeldecken zieht sich ein gelbes Band. Dadurch besitzen die Flügeldecken zusammen eine x-förmige Zeichnung wie manche Arten der Gattung Lordithon. Die Flügeldeckennaht schwarz, nur an der Spitze gelb, Epipleuren dunkel, nur in den Hinterwinkeln gelb, Abdomen dunkelbraun bis schwarz mit breiten gelben Hinterrändern der Segmente. Hinterleibsspitze ebenfalls teilweise hell. Beine gelbbraun, Labrum braun, Taster ebenfalls gebräunt. Fühler an der Basis gelbbraun, zur Spitze dunkler.

Kopf mittelbreit, die Kopfbreite aber noch deutlich kleiner als die Halsschildlänge $(0,91)$, die Augen nicht weit aus dem Kopfumriß hervortretend. Oberfläche glänzend mit feiner und weitläufiger Mikropunktur, in der keine sichtbare Behaarung inseriert (wahrscheinlich abgerieben). Fühler gestreckt, Glied 10 kaum länger als breit.

Halsschild quer (Breite : Länge 1,44 beim Holotypus). Vorderrand und die Seitenränder deutlich, der Hinterrand fein bis auf die Mitte gerandet. Vorderecken nach unten umgebogen, rechtwinklig kurz abgerundet, Hinterecken völlig abgerundet. An Vorder-, Seiten- und Hinterrand mit den gattungstypischen Borstenpunkten (je vier), in denen schwarze kräftige Tastborsten inserieren. Oberfläche glänzend mit weitläufiger erloschener Mikropunktur, in der winzige tomentartige Haare von ca. $15 \mu \mathrm{m}$ Länge inserieren (meist abgerieben).

Schildchen abgerundet dreieckig, vollständig unter dem Halsschild verborgen.

Flügeldecken (Fig. 5) etwa so lang wie zusammen breit (Schulterlänge : Breite 1,02), ihre Nahtlänge nur wenig breiter als die Halsschildlänge $(1,05)$. Flügeldecken mit feiner Grundpunktur (Punktabstand ca. $40 \mu \mathrm{m}$ ), in der eine feine anliegende Grundbehaarung von ca. $60 \mu \mathrm{m}$ Länge inseriert. Neben der Grundpunktur finden sich auf den Flügeldecken meist ein Humeralborstenpunkt, ein Sublateralborstenpunkt, zwei Reihen Diskalborstenpunkte, meist zwei Suturalborstenpunkte sowie 4 Apikal- und 4-5 Lateralborstenpunkte, in denen kräftige und abstehende Tastborsten von bis zu $140 \mu \mathrm{m}$ Länge inserieren. Variabilität der Flügeldeckenbeborstung siehe Tabelle. Hautflügel lang, unter den Flügeldecken gefaltet.

Hinterleib nach Hinten zugespitzt, die Oberfläche der Segmente ähnlich wie die Flügeldecken punktiert und mit anliegender Grundbehaarung versehen. Segmente III bis VII an den Seiten mit langen Tastborsten, Segmente VIII bis X mit zahlreichen Tastborsten von bis zu 0,4 mm Länge. Tergit VII mit deutlichem Hautsaum zum Zusammenfalten der Hautflügel.

Beine wie bei den anderen Arten der Gattung gebildet. 


\begin{tabular}{|l|c|c|c|c|c|c|}
\hline $\mathrm{n}=6$ & 0 Borsten & 1 Borste & 2 Borsten & 3 Borsten & 4 Borsten & 5 Borsten \\
\hline Humeral & 83 & 17 & 0 & 0 & 0 & 0 \\
\hline Sublateral & 0 & 33 & 66 & 0 & 0 & 0 \\
\hline Diskal (innen) & 0 & 33 & 50 & 17 & 0 & 0 \\
\hline Diskal (Mitte) & 0 & 0 & 0 & 100 & 0 & 0 \\
\hline Diskal (außen) & 100 & 0 & 0 & 0 & 0 & 0 \\
\hline Sutural & 0 & 0 & 83 & 17 & 0 & 0 \\
\hline Apikal & 0 & 0 & 0 & 0 & 100 & 0 \\
\hline Lateral & 0 & 0 & 0 & 0 & 50 & 50 \\
\hline
\end{tabular}

Tab. 5: Variabilität der Flügeldeckenbeborstung der japanischen Exemplare von Tachyporus klapperichi SCHÜLKE.

\begin{tabular}{|l|c|c|c|c|c|c|}
\hline $\mathrm{n}=6$ & 0 Borsten & 1 Borste & 2 Borsten & 3 Borsten & 4 Borsten & 5 Borsten \\
\hline Humeral & 0 & 100 & 0 & 0 & 0 & 0 \\
\hline Sublateral & 0 & 0 & 100 & 0 & 0 & 0 \\
\hline Diskal (innen) & 67 & 33 & 0 & 0 & 0 & 0 \\
\hline Diskal (Mitte) & 0 & 0 & 0 & 100 & 0 & 0 \\
\hline Diskal (außen) & 100 & 0 & 0 & 0 & 0 & 0 \\
\hline Sutural & 0 & 17 & 83 & 0 & 0 & 0 \\
\hline Apikal & 0 & 0 & 0 & 0 & 100 & 0 \\
\hline Lateral & 0 & 0 & 0 & 0 & 0 & 100 \\
\hline
\end{tabular}

Tab. 6: Variabilität der Flügeldeckenbeborstung der Typen von Tachyporus klapperichi SCHÜLKE.

Mikroskulptur: Kopf und Halsschild ohne sichtbare Mikroskulptur, Flügeldecken mit feiner querliniger Mikroskulptur (ca. 3 Maschen/10 $\mu \mathrm{m}$ ), Hinterleib ebenfalls fein aber enger als die Flügeldecken chagriniert (ca. 4 Maschen/10 $\mu \mathrm{m}$ ).

Männchen: Vordertarsenglieder 1-3 sehr kräftig erweitert, Mitteltarsen einfach, Sternit VIII am Hinterrand mit tiefem Mittelausschnitt, Der Aedoeagus des einzigen aus Japan vorliegenden Männchens (Fig. 25) ist nur schwach sklerotisiert und stark verformt. Er ist deshalb nur beschränkt auswertbar. Der Aedoeagus besitzt schwach sklerotisierte Zentralstrukturen und ein längliches Basalsklerit.

Weibchen: Vordertarsen nur wenig erweitert, Tergit VIII mit drei tiefen Einschnitten, vierzipfelig.

Bemerkung: Die vorliegenden Exemplare unterscheiden sich in der Flügeldeckenbeborstung von den in China (Fukien) gesammelten Typen von klapperichi durch die teilweise unterschiedliche 
Humeral- und innere Diskalbeborstung der Flügeldecken, so daß ich sie zunächst neu beschreiben wollte. Da sich im Rahmen dieser Studie auch bei anderen ostasiatischen Vertretern, besonders der atriceps-Gruppe, eine erhebliche Variabilität der Flügeldeckenbeborstung ergab, betrachte ich sie vorerst als zu klapperichi gehörend, da weder die Mikroskulptur noch der Bau des Aedoeagus sichtbare Unterschiede ergeben. Diese Hypothese muß aber durch Untersuchung weiteren Materials (besonders genitaliter auswertbarer $\delta$ aus Japan) noch abgesichert werden.

\section{Tachyporus celatus SHARP, 1874}

\section{Typenmaterial}

Lectotypus: Japan (gelb) / Type (rund mit rotem Rand) / Japan, G. Lewis / Sharp. Coll. 1905313 / Tachyporus celatus type D.S. / altes Aufklebeplättchen / Lectotypus - $\delta$, Tachyporus celatus Sharp, 1874, des. M. Schülke 1995. Hiermit designiert!

Paralectotypen: gleiche Daten wie der Lectotypus, 1 Ex. (BMNH); Japan, G.Lewis, Sharp Coll. 1905-313, bzw. 1910-320, 7 Ex. (BMNH). Alle Paralectotypen wurden mit einem Etikett versehen: Paralectotypus, Tachyporus celatus Sharp, 1874, des. M. Schülke 1995. Wahrscheinlich sind auch einige der unten aufgeführten weiteren Exemplare aus Collection Sharp als Syntypen zu bewerten, dies ist jedoch nicht sicher. Ein Teil der Exemplare mit konkreten Fundortangaben ist durch das spätere Sammeldatum auf jeden Fall als Syntypen auszuschließen. Tachyporus celatus SHARP wurde nach einer unbestimmten Anzahl von Exemplaren aus Japan, ohne genaue Fundortangaben beschrieben. Aus dem BMNH lag eine große Serie der Art aus Collection Sharp zur Untersuchung vor, zu der auch Syntypen der Art gehören. Da sich in der Syntypenserie von Tachyporus celatus mehrere Arten befinden, ist die Festlegung eines Lectotypus zwingend notwendig. Der Lectotypus ist komplett erhalten, er wurde umpräpariert, die Hinterleibsspitze wurde abgetrennt, der Aedoeagus herauspräpariert und der Aedoeagus und die Hinterleibssegmente ab VIII in Kanadabalsam eingebettet und unter dem Lectotypus montiert. Die Paralectotypen sind zum großen Teil komplett erhalten und auf Plättchen geklebt, in Einzelfällen fehlen Fühler oder Beine ganz oder teilweise.

\section{Weiteres Material}

Nagasaki, 22.V.-3.VI.81, 1 Ex. (BMNH); Japan, 19.4.81, Lewis, 2 Ex. (BMNH); Nagasaki, 9.3.81, G. Lewis, 2 Ex. (BMNH); Yokohama, 28.IX.-3.XI.81, Lewis, 2 Ex. (BMNH); Nagasaki, G. Lewis, 1 Ex. (BMNH); Hakodate, G. Lewis, 1 Ex. (BMNH); Nikko, G. Lewis, 1 Ex. (BMNH); Kojorou, Mts. Hira, Shiga, Japan, 4.5.1995, N. Ito, 4 Ex. (DEI, cSCHÜ); Mt. Ohyama, Kanagawa, Japan, 4.6.1994, N. Ito, 12 Ex. (DEI, cSCHÜ); Toride, Riv. Tone, Ibaragi, Japan, 2.6.1994, N. Ito, 2 Ex. (DEI, cSCHÜ); Uneno, Hyogo, Japan, 2.5.1994, N. Ito, 1 Ex. (DEI); Nogi, Tochigi, Japan, 3.6.1994, N. Ito, 3 Ex. (DEI, cSCHÜ); Sasabe, Hyogo, 28.5.1994, N. Ito, 2 Ex. (DEI); Yawata, Riv. Yodo, Kyoto, 16.5.1993, N. Ito, 1 Ex. (DEI); Japan, Mt. Tahao, leg. Yoshida Wada, 17.7.53, 2 Ex. (NHMW); Japan, Hyogo, Mt. Maya, 9.IV.1994, leg. N. Ito, 1 Ex. (DEI).

\section{Ergänzungen zur Beschreibung}

Meßwerte des Lectotypus (in mm): Kopfbreite: 0,63; Halsschildbreite: 1,07; Halsschildlänge: 0,74 ; Flügeldeckennahtlänge: 0,86 ; Flügeldeckenschulterlänge: 1,08 ; Flügeldeckenbreite: 1,13 ; Vorderkörperlänge: 2,03; Gesamtlänge: 3,38 ; Aedoeaguslänge: 0,78 .

Flügeldeckenbeborstung des Lectotypus (links/rechts): Humeral: 1/1; Sublateral: 1/1; Diskal (innen): 1/1; Diskal (Mitte): 3/3; Diskal (außen): 2/1; Sutural: 3/3; Apikal: 4/4; Lateral: 5/5. Kopf schwarz, Halsschild einfarbig rotbraun, die Ränder schwach aufgehellt. Flügeldecken rotbraun, Seitenrand und Basis etwas dunkler, Hinterleib dunkelbraun, die Hinterränder der Seg- 
mente rötlich aufgehellt. Beine gelbbraun, Fühlerbasis (Glieder 1 und 2) gelb, die weiteren Glieder dunkler, ab Glied 5 dunkelbraun.

Fühlerglied 10 deutlich länger als breit. Kiefertaster mit angedunkelten Gliedern 3 und 4. Tergit VII am Hinterrand mit einem deutlichen Hautsaum.

Variabilität der Zeichnung: Kopf schwarz, Halsschild gelbrot bis rotbraun, Mitte teilweise mit undeutlicher Diskalmakel (wie bei T. caucasicus oder größer). Flügeldecken (Fig. 6) einfarbig hellbraun bis umfangreich dunkelbraun bis schwarz gefärbt, manchmal mit undeutlicher kleiner Diskalmakel, teilweise mit ausgedehnter dunkler Zeichnung (vergleichbar mit Tachyporus hypnorum "var. armeniacus" aber nicht so dunkel wie bei dieser Art).

\begin{tabular}{|l|c|c|c|c|c|c|}
\hline $\mathrm{n}=34$ & 0 Borsten & 1 Borste & 2 Borsten & 3 Borsten & 4 Borsten & 5 Borsten \\
\hline Humeral & 3 & 97 & 0 & 0 & 0 & 0 \\
\hline Sublateral & 0 & 82 & 18 & 0 & 0 & 0 \\
\hline Diskal (innen) & 0 & 6 & 94 & 0 & 0 & 0 \\
\hline Diskal (Mitte) & 0 & 0 & 6 & 94 & 0 & 0 \\
\hline Diskal (außen) & 3 & 94 & 3 & 0 & 0 & 0 \\
\hline Sutural & 0 & 0 & 9 & 91 & 0 & 0 \\
\hline Apikal & 0 & 0 & 0 & 0 & 100 & 0 \\
\hline Lateral & 0 & 0 & 0 & 0 & 9 & 91 \\
\hline
\end{tabular}

Tab. 7: Variabilität der Flügeldeckenbeborstung von Tachyporus celatus SHARP.

Mikroskulptur: Kopf und Halsschild glatt und ohne Mikroskulptur, Flügeldecken weitläufig quer mikroskulpturiert (3 Maschen/10 $\mu \mathrm{m}$ ), teilweise nur auf dem hinteren Drittel der Flügeldecken deutlich, Hinterleib feiner und enger chagriniert (4-5 Maschen/10 $\mu \mathrm{m}$ ).

Aedoeagus (Fig. 18) schlank, ohne auffällige Medianstrukturen, mit gebogenem, schlankem Sklerit.

Tachyporus celatus ist in Ostasien weit verbreitet und gehört auf Grund der Oberflächenskulptur, der Beborstung und des Genitalbaus zur weiteren Verwandtschaft von Tachyporus chrysomelinus (LINNÉ) und ist hier Tachyporus pusillus GRAVENHORST am ähnlichsten.

\section{Tachyporus celatoides sp. n.}

\section{Typenmaterial}

Holotypus- $\varnothing^{\dagger}$ Japan, G. Lewis / Sharp Coll. 1905-313. / T. celatus var. / M. Schülke, Berlin, Zeichnung - Nr. 271/95 / Paralectotypus- $ð$, Tachyporus celatus Sharp, 1874, des. M. Schülke 1995 / Holotypus-ð̊, Tachyporus celatoides sp. n., det. M. Schülke 1995 (BMNH)

Paratypen: Tachyporus celatus D.S., Kumawoda Jap., 15.4.81 Lewis / Japan, G. Lewis / Sharp Coll. 1905-313. / No Type of T. celatus / 1 Ex. (BMNH); Tachyporus celatus D.S., Chiuzenji, Japan, 20.08.1881, Lewis / Japan, G. Lewis / Sharp Coll. 1905-313 / No Type of T. celatus / 1 Ex. (cSCHÜ); Japan, G. Lewis, 1910-320 / Paralectotypus, Tachyporus celatus Sharp, 1874, des. M. Schülke 1997, 2 Ex, (BMNH, cSCHÜ); Yokohama, Japan, G. Lewis, 1910-320, 2 Ex. 
(BMNH); Nikaido, 14.6.81, / Japan, G. Lewis, 1910-320, 1 Ex. (BMNH); Japan, Honshu, B.M. 1980-492, P.M. Hammond / Kyoto, 7.IX.80, litter in park, 1 Ex. (BMNH); Japan, Honshu B.M. 1980-492, P.M. Hammond / Kyoto, Palace Gdns, 7.-20. VIII.80, 2 Ex. (BMNH, cSCHÜ); Japan, Kasagi, Riv. Kizu, Nara, 3.5.1995, N. Ito, 1 Ex. (DEI); Japan, Toride, Riv. Tone, Ibaragi, 2.6.1994, N. Ito, 2 Ex. (DEI, cSCHÜ); Japan, Mt. Myoken, Osaka, 25.VI. 1993, N. Ito, 4 Ex. (DEI, cSCHÜ); Mt. Ohyama, Kanagawa, Japan, 4.VI.1994, N. Ito, 1 Ex. (DEI).

\section{Beschreibung und Differentialdiagnose}

Meßwerte des Holotypus (in mm): Kopfbreite: 0,63; Halsschildbreite: 1,08; Halsschildlänge: 0,73 ; Flügeldeckennahtlänge: 0,77 ; Flügeldeckenschulterlänge: 0,97 ; Flügeldeckenbreite: 1,05 ; Vorderkörperlänge: 1,84; Gesamtlänge: 3,35; Aedoeaguslänge: 0,81.

Längenverhältnisse der Fühlerglieder 1-11: 3,75:2,75:2,5:3:3:3:2,75:2,5:2,25:2,25:4,5.

Länge zu Breite, Glied 1: 2,68; Glied 2: 2,29; Glied 5: 1,71; Glied 9: 1,0; Glied 10: 0,80; Glied 11: 1,50.

Flügeldeckenbeborstung des Holotypus (links/rechts): Humeral: 0/0; Sublateral: 1/1; Diskal (innen): 0/0; Diskal (Mitte): 3/2; Diskal (außen): 0/0; Sutural: 1/1; Apikal: 2/2; Lateral: 3/3. Kopf schwarz, glänzend, Halsschild, Schildchen, Flügeldecken und Epipleuren einfarbig gelbrot, Hinterleib dunkelbraun bis pechschwarz, Hinterränder der Segmente breit aufgehellt. Beine und Mundteile gelb, Fühlerbasis gelb, ab Glied 5 wenig gebräunt.

Kopf schmal, über den Augen die größte Breite erreichend, Augen wenig aus dem Kopfumriß hervortretend. Fühler wenig gestreckt, die vorletzten Glieder nicht länger als breit oder leicht quer.

Halsschild quer (Länge : Breite 0,68), Vorderecken nach vorn unten vorgezogen, gerundet rechtwinklig, Hinterecken breit abgerundet, an allen Seiten deutlich gerandet und innerhalb des Seitenrandes mit den für Tachyporus typischen Borstenpunkten versehen.

Flügeldecken (Fig. 7) etwas breiter als lang (Breite zu Schulterlänge: 1,08), Schultern deutlich entwickelt. Die Flügeldecken tragen neben einer sehr feinen Grundpunktierung, in der eine unscheinbare anliegende Behaarung inseriert, eine größere Anzahl \pm reihig angeordneter langer Tastborsten. Die Seitenrandborsten (Lateralborsten) sind 1,5 - 2 x so lang wie die Mittelschienenbreite. Hautflügel lang.

\begin{tabular}{|l|c|c|c|c|c|}
\hline $\mathrm{n}=26$ & 0 Borsten & 1 Borste & 2 Borsten & 3 Borsten & 4 Borsten \\
\hline Humeral & 100 & 0 & 0 & 0 & 0 \\
\hline Sublateral & 0 & 100 & 0 & 0 & 0 \\
\hline Diskal (innen) & 100 & 0 & 0 & 0 & 0 \\
\hline Diskal (Mitte) & 0 & 0 & 12 & 88 & 0 \\
\hline Diskal (außen) & 100 & 0 & 0 & 0 & 0 \\
\hline Sutural & 0 & 68 & 32 & 0 & 0 \\
\hline Apikal & 0 & 0 & 100 & 0 & 0 \\
\hline Lateral & 0 & 0 & 0 & 35 & 65 \\
\hline
\end{tabular}

Tab. 8: Variabilität der Flügeldeckenbeborstung von Tachyporus celatoides sp. n. 
Tachyporus celatoides sp. $\mathrm{n}$. besitzt keine Humeralborstenpunkte, eine Sublateralborste, eine Suturalborste, zwei Apikalborsten, drei bis vier Lateralborsten und nur eine Reihe von Diskalborsten mit zwei bis drei Borsten auf der Scheibe der Flügeldecken.

Die Variabilität der Flügeldeckenbeborstung ist relativ gering. Wie bei fast allen bekannten Arten der Gattung erwiesen sich besonders die Humeralborste und die Sublateralborsten als sehr konstant.

Hinterleib konisch zugespitzt, fein punktiert, seitlich an den Rändern der Segmente mit langen Tastborsten versehen. Tergit VII mit deutlichem Hautsaum. Beine relativ schlank, wie bei den anderen Arten der Gattung gebaut.

Mikroskulptur: Kopf, Halsschild und Flügeldecken ohne sichtbare Mikroskulptur, Hinterleib mit deutlicher Mikroskulptur von 4 Maschen $/ 10 \mu \mathrm{m}$.

Männchen: Sternit VIII dreieckig ausgerandet, Vordertarsenglieder 1-4 wenig erweitert, Aedoeagus (Fig. 19, 26) schlank und schmal, mit wenig sklerotisierten Zentralstrukturen und einem besonders apikal nur schwach sklerotisierten Basalsklerit.

Weibchen: Tergit VIII vierzipfelig, Sternit VIII am Hinterrand mit einem hellen Borstensaum, Vordertarsen schlank.

Verwandtschaftliche Stellung: Tachyporus celatoides gehört wie Tachyporus celatus zur chrysomelinus-Gruppe. Beide Taxa sind aber keine Schwesterarten.

Derivatio Nominis: Der Artname celatoides wird von der Art abgeleitet, von der die neue Art abgetrennt wird, von Tachyporus celatus SHARP.

Verbreitung: Japan (Honshu)

Differentialdiagnose: Tachyporus celatoides wurde bisher mit hell gefärbten Exemplaren von Tachyporus celatus SHARP verwechselt. Durch die Flügeldeckenbeborstung erinnert die Art auch an Tachyporus abdominalis (FABRICIUS) oder Tachyporus ruficollis GRAVENHORST, sie ist mit beiden Arten jedoch nicht verwandt und unterscheidet sich von beiden Arten durch die längeren Flügeldecken, von ruficollis auch durch den schmalen Kopf. Von Tachyporus celatus, mit dem die Art bisher konfundiert wurde, unterscheidet sie sich durch die fehlende Mikroskulptur der Flügeldecken und die reduzierte Flügeldeckenbeborstung.

\section{Tachyporus chrysomelinus (LINNÉ, 1758)}

\section{Material}

Russia or., Sakhalin, Korsakov distr., 3 km W Kirillovo vill., Uryun river, 22.-23.VII.1993, leg. Pütz \& Wrase (cSCHÜ); Russia or., Sakhalin, Korsakov distr., Ismenshyroye lake, 21.22.VII.1993, leg. Pütz \& Wrase, 1 Ex. (cSCHÜ); Russia, Sakhalin, Aniva distr., 5 km W Aniva, 25.VII.1993, leg. Pütz \& Wrase, 1 Ex. (cSCHÜ); Russia, Sakhalin, Aniva distr., Vysokoye vill., valley of Luytoga river, 22.-23.VII.1993, leg. Pütz \& Wrase, 4 Ex. (cPÜTZ, cSCHÜ); Russia, Sakhalin, Aniva distr., $5 \mathrm{~km}$ W Petropavlovskiy, tributary of Lyutoga river, 20.-21.VII.1993, leg. Pütz \& Wrase, 1 Ex. (cPÜTZ).

\section{Beschreibung der Exemplare von Sachalin}

Meßwerte ( ${ }^{\star}$ aus Kirillovo) (in mm): Kopfbreite: 0,70; Halsschildbreite: 1,25; Halsschildlänge: 0,82 ; Flügeldeckennahtlänge: 0,92 ; Flügeldeckenschulterlänge: 1,23; Flügeldeckenbreite: 1,22 ; Vorderkörperlänge: 2,09; Gesamtlänge: 4,00; Aedoeaguslänge: 0,93.

Längenverhältnisse der Fühlerglieder 1-11: 9:6:7:6,5:7,5:7:7:7:6,25:5,75:10,25.

Verhältnis Länge/Breite von Fühlerglied 5: 2,31; 7: 1,75; 9: 1,25; 10: 1,10 und 11: 1,71.

Färbung: Kopf schwarz, Halsschild gelbrot mit einem braunen schmalen Diskalfleck, Schildchen 
braun bis schwarz, Flügeldecken gelbrot mit braun bis schwarz gefärbter Skutellarregion und dunkler Vorderhälfte des Seitenrandes. Die Verdunklung an Seitenrand der Flügeldecken betrifft auch die Epipleuren. Abdomen dunkelbraun bis schwarz mit breit aufgehellten Hinterrändern der Segmente. Beine, Labrum und Taster gelb. Fühler mit drei bis vier gelben Basalgliedern, die folgenden Glieder undeutlich gebräunt.

Kopf klein, die Kopfbreite deutlich geringer als die Halsschildlänge $(0,85)$, die Augen nicht aus dem Kopfumriß hervorragend. Die Oberfläche glänzend, mit sehr feiner und weitläufiger Punktur (ohne Behaarung). Fühler gestreckt, die vorletzten Glieder länger als breit. Halsschild quer (Breite : Länge 1,53), Vorderrand breit, die Seitenränder schmaler, der Hinterrand mit Ausnahme eines kleinen Bereichs in der Mitte fein gerandet. An Vorder-, Seiten- und Hinterrand befinden sich jeweils vier Tastborsten. Vorderecken nach unten gebogen, kurz abgerundet rechtwinklig, Hinterecken sehr breit abgerundet. Oberfläche glänzend, ohne Punktur und Behaarung. Schildchen abgerundet dreieckig, vollständig unter dem Halsschild verborgen. Flügeldecken (Fig. 8) so lang wie breit (Schulterlänge : Breite 1,01), ihre Nahtlänge länger als die Halsschildlänge $(1,12)$. Flügeldecken mit feiner Grundpunktur (Punktabstand 30 bis $40 \mu \mathrm{m}$ ) in der eine feine anliegende Grundbehaarung inseriert (Länge der Behaarung ca. $60 \mu \mathrm{m}$ ). Neben der Grundpunktur befinden sich auf den Flügeldecken ein bis (selten) zwei Sublateralborstenpunkte, zwei Reihen Diskalborstenpunkte, meist ein Suturalborstenpunkt und je drei Apikal- und Lateralborstenpunkte. In den Borstenpunkten inserieren kräftige schwarze Tastborsten von ca 80-120 $\mu \mathrm{m}$ Länge. Variabilität der Flügeldeckenchaetotaxie siehe Tabelle. Hautflügel lang.

\begin{tabular}{|l|c|c|c|c|c|}
\hline $\mathrm{n}=16$ & 0 Borsten & 1 Borste & 2 Borsten & 3 Borsten & 4 Borsten \\
\hline Humeral & 100 & 0 & 0 & 0 & 0 \\
\hline Sublateral & 0 & 93 & 7 & 0 & 0 \\
\hline Diskal (innen) & 0 & 25 & 69 & 6 & 0 \\
\hline Diskal (Mitte) & 0 & 12 & 88 & 0 & 0 \\
\hline Diskal (außen) & 100 & 0 & 0 & 0 & 0 \\
\hline Sutural & 12 & 63 & 25 & 0 & 0 \\
\hline Apikal & 0 & 0 & 0 & 100 & 0 \\
\hline Lateral & 0 & 0 & 0 & 88 & 12 \\
\hline
\end{tabular}

Tab. 9: Variabilität der Flügeldeckenbeborstung von Tachyporus chrysomelinus (LINNÉ) (nur Exemplare von Sachalin).

Hinterleib wie bei allen Arten der Gattung konisch zugespitzt. Die Oberfläche der Segmente in ähnlicher Weise wie die Flügeldecken punktiert und behaart. An den Seiten der Hinterleibssegmente befinden sich kräftige lange Tastborsten (bis 0,5 mm), die Hinterleibsspitze ab Segment VIII ist mit Zahlreichen Tastborsten versehen. Tergit VII besitzt am Hinterrand einen deutlichen Hautsaum zum Zusammenfalten der Hautflügel. Beine wie bei den anderen Arten der Gattung gebaut.

Mikroskulptur: Kopf und Halsschild glatt, ohne erkennbare Mikroskulptur, Flügeldecken auf der ganzen Fläche kräftig querlinig chagriniert (Maschenweite 2-3 Maschen/10 $\mu \mathrm{m}$ ), Hinterleib mit engerem, quermaschigem Chagrin (4 Maschen/10 $\mu \mathrm{m}$ ). 
Männchen: Vordertarsenglieder 1-3 erweitert, aber alle Glieder deutlich länger als breit, Mitteltarsen einfach, Sternit VIII mit abgerundet dreieckigem Einschnitt am Hinterrand, Aedoeagus (Fig. 27) schlank, mit deutlicher schmaler Zentralstruktur und langem schlanken Basalsklerit. Weibchen: Vordertarsenglieder 1-3 etwas weniger als beim $\delta$ erweitert, Tergit VIII mit drei tiefen Einschnitten am Hinterrand, vierzipfelig.

Tachyporus chrysomelinus ist hauptsächlich im nördlichen Teil der Westpaläarktis verbreitet und besiedelt den südlichen Teil dieses Gebietes (Mittelmeerraum, Kaukasus, Mittelasien) meist nur in gebirgigen Lagen. Über die Verbreitung der Art in Sibirien ist nur wenig bekannt, sie wurde aber auch aus Japan gemeldet. Die vorliegenden Tiere unterscheiden sich von europäischen chrysomelinus durch das regelmäßige Auftreten eines dunklen Diskalflecks auf dem Pronotum (was ich bisher sonst nur von wenigen aus dem Baikalgebiet und dem Altai vorliegenden Belegen (MNHUB) gesehen habe), die Flügeldeckenchaetotaxie, die Mikroskulptur und auch der Bau des Aedoeagus inklusive der Größe und Form des Basalsklerits liegen jedoch innerhalb der Variationsbreite von chrysomelinus. Die Art könnte durchaus auch in Japan vorkommen, Belege lagen bisher von dort jedoch nicht vor. Die Meldung von HIRASHIMA (1989) könnte auch auf einer Verwechslung mit celatoides sp. $\mathrm{n}$. beruhen.

\section{Tachyporus wrasei sp. n.}

\section{Typenmaterial}

Holotypus: Russia, Sakhalin, Tymovskiy distr., Zonalnoye vill., $10 \mathrm{~km} \mathrm{~S} \mathrm{Palevo,} \mathrm{15./19.VII.}$ 1993, Pütz \& Wrase (cSCHÜ).

Paratypen: gleiche Funddaten wie der Holotypus, 7 Ex. (cPÜTZ, cSCHÜ).

\section{Beschreibung und Differentialdiagnose}

Meßwerte des Holotypus (in mm): Kopfbreite: 0,63; Halsschildbreite: 1,09; Halsschildlänge: 0,73; Flügeldeckennahtlänge: 0,77; Flügeldeckenschulterlänge: 1,08; Flügeldeckenbreite: 1,08; Vorderkörperlänge: 2,15; Gesamtlänge: 4,06; Aedoeaguslänge: 0,85.

Längenverhältnisse der Fühlerglieder 1-11: 7,5:5:6:6:6,25:6,25:6:5,5:5,5:5:9,5.

Verhältnis Länge/Breite von Fühlerglied 5: 2,08; 7: 1,50; 9: 1,16; 10: 1,04 und 11: 1,65. Flügeldeckenbeborstung des Holotypus (links/rechts): Humeral: 0/0; Sublateral: 1/1; Diskal (innen): 2/2; Diskal (Mitte): 2/2; Diskal (außen): 0/0; Sutural: 0/0; Apikal: 2/2; Lateral: 3/3.

Färbung: Kopf schwarz, Halsschild einfarbig dunkel gelbrot, meist mit einem großen, am Vorderrand breiteren braunen Diskalfleck, Schildchen dunkelbraun, Flügeldecken rötlich, die Umgebung des Schildchens und der Seitenrand bis auf das letzte Drittel braun bis schwarz angedunkelt. Die Verdunklung des Seitenrandes reicht auch auf die Epipleuren. Abdomen dunkelbraun bis schwarz mit breit aufgehellten Hinterrändern der Tergite, die Segmente VIII bis $\mathrm{X}$ dunkel, Beine gelb, Labrum, Taster und Fühlerbasis gelb, die beiden letzten Glieder der Kiefertaster bei einigen Exemplaren bräunlich, Fühler ab Glied 5 zunehmend angedunkelt.

Im ganzen bis auf die dunkle Mitte des Halsschildes sehr ähnlich Tachyporus chrysomelinus (LINNÉ) gefärbt.

Kopf klein, die Kopfbreite wesentlich kleiner als die Halsschildlänge ( 0,86 beim Holotypus), die Augen nicht aus dem Kopfumriß hervorragend. Die Oberfläche glänzend mit kaum sichtbarer mikroskopisch feiner und weitläufiger Punktur. Fühler gestreckt, die vorletzten Glieder wenig länger als breit. Halsschild quer (Breite : Länge 1,49 beim Holotypus), sein Vorderrand breit, die Seitenränder schmaler, der Hinterrand nur in den Außenecken fein gerandet. An Vorder-, Seiten- und Hinterrand befinden sich je vier Borstenpunkte mit kräftigen dunklen Tastborsten. Vorderecken nach unten gebogen, kurz abgerundet rechtwinklig, die Hinterecken völlig abge- 
rundet. Oberfläche glänzend, ohne sichtbare Punktierung oder Behaarung. Schildchen abgerundet dreieckig, völlig unter dem Hinterrand des Halsschildes verborgen. Flügeldecken (Fig. 9) so lang wie breit (Schulterlänge : Breite beim Holotypus 1,0), ihre Nahtlänge aber nur wenig größer als die Halsschildlänge (1,05 beim Holotypus). Flügeldecken mit feiner Grundpunktur (Punktabstand 30-50 $\mu \mathrm{m}$ ), in der eine feine anliegende Grundbehaarung inseriert (Länge der Behaarung ca. $50 \mu \mathrm{m}$ ). Neben der Grundpunktur befinden sich auf den Flügeldecken ein Sublateralborstenpunkt, zwei Reihen Diskalborstenpunkte, meist zwei Apikal- und drei Lateralborstenpunkte, selten auch ein Suturalborstenpunkt. In den Borstenpunkten inserieren kräftige dunkle Tastborsten von ca. $110 \mu \mathrm{m}$ Länge. Variabilität der Flügeldeckenchaetotaxie siehe Tabelle. Hautflügel lang.

\begin{tabular}{|l|c|c|c|c|}
\hline $\mathrm{n}=16$ & 0 Borsten & 1 Borste & 2 Borsten & 3 Borsten \\
\hline Humeral & 100 & 0 & 0 & 0 \\
\hline Sublateral & 0 & 100 & 0 & 0 \\
\hline Diskal (innen) & 0 & 0 & 100 & 0 \\
\hline Diskal (Mitte) & 0 & 0 & 94 & 6 \\
\hline Diskal (außen) & 100 & 0 & 0 & 0 \\
\hline Sutural & 81 & 19 & 0 & 0 \\
\hline Apikal & 0 & 0 & 88 & 12 \\
\hline Lateral & 0 & 0 & 0 & 100 \\
\hline
\end{tabular}

Tab. 10: Variabilität der Flügeldeckenbeborstung von Tachyporus wrasei sp. n.

Hinterleib wie bei allen Arten der Gattung konisch zugespitzt, die Oberfläche der Segmente in gleicher Dichte und Stärke wie die Flügeldecken punktiert und fein anliegend behaart. An den Seiten der Hinterleibssegmente befinden sich lange Tastborsten, die Segmente VIII bis X mit zahlreicheren Tastborsten bis 0,45 mm Länge.

Tergit VII besitzt am Hinterrand einen deutlichen Hautsaum zum Zusammenfalten der Hautflügel. Beine wie bei den anderen Arten der Gattung.

Mikroskulptur: Kopf und Halsschild glänzend, ohne sichtbare Mikroskulptur, Flügeldecken sehr weitläufig und schwach mikroskulpturiert, bei einem Teil der vorliegenden Exemplare ist das Chagrin auf der Vorderhälfte der Flügeldecken völlig verloschen, nur vor dem Hinterrand deutlich, Maschenweite der querlinigen Mikroskulptur ca. 2 Maschen/10 $\mu \mathrm{m}$, Hinterleib etwas enger als die Flügeldecken und deutlicher als dort quermaschig chagriniert (Maschenweite etwa $3 \mathrm{Maschen} / 10 \mu \mathrm{m})$.

Männchen: Vordertarsenglieder 1 und 2 kräftig, Glied 3 weniger kräftig erweitert, alle Glieder aber deutlich länger als breit. Mitteltarsen einfach, Sternit VIII mit deutlichem, abgerundeten Mitteleinschnitt am Hinterrand, Aedoeagus (Fig. 28-30) schlank mit deutlich verbreiterter Zentralstruktur und langem Basalsklerit.

Weibchen: Vordertarsenglieder 1 und 2 nur wenig, Glied 3 nicht erweitert, Tergit VIII mit drei tiefen Einschnitten am Hinterrand, vierzipfelig. 
Derivatio Nominis: Die Art wird einem ihrer Sammler, dem Berliner Carabidologen David Wrase gewidmet.

Tachyporus wrasei ist dem paläarktischen Tachyporus chrysomelinus (LINNÉ) ähnlich und auch nahe mit dieser Art verwandt. Er unterscheidet sich von chrysomelinus und dispar (PAYKULL) durch die breiter gebaute Zentralstruktur im Medianlobus des Aedoeagus und das regelmäßige Fehlen von Suturalborsten auf den Flügeldecken.

\section{Tachyporus terminalis SHARP, 1888 \\ (= Tachyporus manchuricus BERNHAUER, 1938 sym. nov。)}

Anläßlich der Bearbeitung ostsibirischer Tachyporus (SCHÜLKE, 1995) wurde die Synonymie beider Taxa vermutet. Nach Untersuchung des Typus von terminalis kann diese Vermutung bestätigt werden. Der Typus von Tachyporus manchuricus BERNHAUER (FMNH) wurde bereits früher untersucht und mit Material aus dem Primorski Kraj und Sachalin verglichen.

\section{Typenmaterial}

Holotypus: Tachyporus terminalis Type D. S., Shimonosuwa, 31.7.1881 [auf Klebeplättchen] / Type [rund mit rotem Rand] / Nagasaki, 13.II.-21.IV.81 / Japan, G. Lewis, 1910-320.

Tachyporus terminalis SHARP wurde nach einem männlichen Einzeltier beschrieben. Der Holotypus ist auf ein Kartonplättchen geklebt und vollständig erhalten.

\section{Weiteres Material}

Russia, Primorsky kr., Partisansky Distr., Alexeyevsky khrebet 20 km E Sergeyevka, Forests nr. Andreyevka river, 400-800 m, 26.-29.07.1993, Pütz \& Wrase, 8 Ex. (cSCHÜ); Russia, Sakhalin, Korsakov distr., $3 \mathrm{~km}$ W Kirilovo vill., Uryun river, 22.-23.07.1993, leg. Pütz \& Wrase, 1 Ex. (cSCHÜ); Russia, Sakhalin, Aniva distr., Novo Alexandrovsk, 10 km N YushneSachalinsk, Zazuya river, 12.07.1993, Pütz \& Wrase, 2 Ex. (cSCHÜ); Russia, Sakhalin, Aniva distr., $5 \mathrm{~km} \mathrm{~W}$ Petropavlovsky, tributary of Lyutoga river, 20.-21.07.1993, leg. Pütz \& Wrase, 1 Ex. (cSCHÜ); Russia, Primorskij kr., Novocugujevka, 15.-20.7.1990, leg. Boukal, 1 Ex. (cSCHÜ); Rußland, Ussuri-Gebiet, Rajon Lazo, Umgeb. v. Lazo, im Garten, 25.IV.1993, leg. Sundukov, 1 Ex. (MNHUB); China, Mandsch., Harbin, 15.9.30, v. Jettmar, 1 Ex. (cSCHÜ); Jesso, Nemuro, Japan, Rost, 1 Ex. (FMNH); Manchourie, Chandaochedzi, 1 Ex. (FMNH); Semenovsk, Altai, 1 Ex. (FMNH).

\section{Ergänzungen zur Beschreibung}

Meßwerte des Holotypus (in mm): Kopfbreite: 0,71; Halsschildbreite: 1,27; Halsschildlänge: 0,82 ; Flügeldeckennahtlänge: 0,82 ; Flügeldeckenschulterlänge: 1,05 ; Flügeldeckenbreite: 1,22 ; Vorderkörperlänge: 1,87; Gesamtlänge: 3,65.

Flügeldeckenbeborstung des Holotypus (links/rechts): Humeral: 0/0; Sublateral: 1/1; Diskal (innen): 1/1; Diskal (Mitte): 0/0; Diskal (außen): 0/0; Sutural: 0/0; Apikal: 2/2; Lateral: 2/2.

Flügeldecken (Fig. 10) etwas schmaler als der Halsschild, Tergit VII mit deutlichem Hautsaum, erstes Glied der Hintertarsen so lang wie 2-4, Fühler schlank, die Glied 9 u. 10 deutlich länger als breit, Vordertarsen des ô erweitert (Glied 1-3).

Mikroskulptur: Kopf und Halsschild glatt, ohne sichtbare Mikroskulptur, Flügeldecken im hinteren Teil mit weitläufigem Chagrin von 1-2 Maschen/10 $\mu \mathrm{m}$, Hinterleib deutlicher und enger (2-3 Maschen/10 $\mu \mathrm{m})$ mikroskulpturiert.

Tachyporus terminalis SHARP besitzt eine variable Färbung der Flügeldecken. Im Normalfall ist eine \pm breite schwarze Basalbinde ausgebildet, die bis zur Hälfte der Flügeldecken einnimmt. Bei einigen Exemplaren ist diese Basalbinde auch teilweise oder fast vollständig reduziert. 


\begin{tabular}{|l|c|c|c|c|}
\hline $\mathrm{n}=28$ & 0 Borsten & 1 Borste & 2 Borsten & 3 Borsten \\
\hline Humeral & 100 & 0 & 0 & 0 \\
\hline Sublateral & 0 & 100 & 0 & 0 \\
\hline Diskal (innen) & 0 & 96 & 4 & 0 \\
\hline Diskal (Mitte) & 93 & 7 & 0 & 0 \\
\hline Diskal (außen) & 100 & 0 & 0 & 0 \\
\hline Sutural & 100 & 0 & 0 & 0 \\
\hline Apikal & 0 & 0 & 100 & 0 \\
\hline Lateral & 0 & 0 & 96 & 4 \\
\hline
\end{tabular}

Tab. 11: Variabilität der Flügeldeckenbeborstung von Tachyporus terminalis SHARP.

Der Holotypus von T. terminalis SHARP besitzt helle Flügeldecken mit einem kleinen dunklen Skutellarfleck, wodurch die Beschreibung von manchuricus (mit deutlichen Basalbinden) verständlich wird. Ein gleich gefärbtes Stück liegt mir auch von Sachalin aus einer größeren Serie von dunkler gefärbten terminalis vor. Tachyporus terminalis unterscheidet sich von Tachyporus obtusus (LINNÉ) durch die kürzeren Flügeldecken und die reduzierte Diskal-Beborstung sowie die bei terminalis auf den Hinterrand der Flügeldecken beschränkte Mikroskulptur. Aedoeagus: Schlank mit deutlichen Zentralstrukturen und langem Sklerit (Fig. 31).

Verbreitung: Tachyporus terminalis SHARP wurde bisher aus Japan (Honshu), Rußland (Primorie, Ost-Sibirien, Sachalin), China (Mandschurei) bekannt. Im Altai-Gebiet kommen Tachyporus terminalis und obtusus offensichtlich gemeinsam vor. Während der o.g. Fundort von terminalis (Semenovsk im Altai $(\mathrm{FMNH})$ ) nicht genau zu lokalisieren war, liegen aus der Umgebung von Barnaul 2 Exemplare von obtusus vor (MNHUB).

\section{Tachyporus frontalis CAMERON, 1933}

\section{Typenmaterial}

Holotypus- $ठ$ : Type [rund, roter Rand] / Japan, Settsu, Katsuoji / T. frontalis Cam. TYPE / M. Cameron, Bequest., B.M. 1955-147 / Holotypus- $\delta^{\star}$, Tachyporus frontalis Cam., 1933, M. Schülke det. 1995

Tachyporus frontalis CAMERON wurde ebenfalls nach einem Einzelstück beschrieben. Der Holotypus war auf ein rechteckiges Plättchen geklebt. Er wurde zur Untersuchung umpräpariert und auf ein neues Plättchen geklebt. Die Hinterleibsspitze (ab Segment VIII) wurde zerlegt und die Einzelteile in Kanadabalsam eingebettet. Dem Holotypus fehlen Schiene und Tarsen des linken Hinterbeines.

\section{Weiteres Material}

Mt. Myoken, Osaka, Japan, 25.6.1993, N. Ito, 2 Ex. (DEI, cSCHÜ).

\section{Ergänzungen zur Beschreibung}

Meßwerte des Holotypus (in mm): Kopfbreite: 0,72; Halsschildbreite: 1,20; Halsschildlänge: 0,80; Flügeldeckennahtlänge: 0,85 ; Flügeldeckenschulterlänge: 1,09 ; Flügeldeckenbreite: 1,18; Vorderkörperlänge: 2,06; Gesamtlänge: 4,06; Aedoeaguslänge: 0,83. 
Flügeldeckenbeborstung des Holotypus (links/rechts): Humeral: 0/0; Sublateral: 0/0; Diskal (innen): 0/0; Diskal (Mitte): 1/1; Diskal (außen): 0/0; Sutural: 0/0; Apikal: 4/4; Lateral: 4/4. Kopf schwarzbraun, Stirn in der Mitte gelb, Hallsschild gelb mit breitem unscharfem braunen Diskalfleck am Vorderrand, Flügeldecken gelbrot, Hinterleib gelbrot, ab Segment VII gebräunt. Beine, Fühler und Mundteile gelb.

\begin{tabular}{|l|c|c|c|c|c|}
\hline $\mathrm{n}=6$ & 0 Borsten & 1 Borste & 2 Borsten & 3 Borsten & 4 Borsten \\
\hline Humeral & 100 & 0 & 0 & 0 & 0 \\
\hline Sublateral & 100 & 0 & 0 & 0 & 0 \\
\hline Diskal (innen) & 100 & 0 & 0 & 0 & 0 \\
\hline Diskal (Mitte) & 0 & 100 & 0 & 0 & 0 \\
\hline Diskal (außen) & 100 & 0 & 0 & 0 & 0 \\
\hline Sutural & 100 & 0 & 0 & 0 & 0 \\
\hline Apikal & 0 & 0 & 0 & 50 & 50 \\
\hline Lateral & 0 & 0 & 0 & 0 & 100 \\
\hline
\end{tabular}

Tab. 12: Variabilität der Flügeldeckenbeborstung von Tachyporus frontalis CAMERON.

Segment VII des Hinterleibs mit deutlichem Hautsaum.

Mikroskulptur: Kopf glänzend ohne Mikroskulptur, Halsschild mit schwacher Mikroskulptur aus queren Linien, am Vorderrand verloschen, Maschenweite $3 \mathrm{Maschen} / 10 \mu \mathrm{m}$. Flügeldecken schwach quer mikroskulpturiert (3 Maschen/10 $\mu \mathrm{m}$ ). Abdomen mit dichterer Mikroskulptur von $4 \mathrm{Maschen} / 10 \mu \mathrm{m}$.

Aedoeagus (Fig. 20) kräftig mit einem paaren Feld feiner Borsten im Zentralbereich und kräftigem Sklerit.

Tachyporus frontalis CAMERON gehört nach Punktierung, Flügeldeckenbeborstung (Fig. 11) und Mikroskulptur in die weitere Verwandtschaft von Tachyporus solutus ERICHSON. Die Art zeichnet sich innerhalb dieser Verwandtschaftsgruppe durch das Vorhandensein von Mikroskulptur auf dem Halsschild aus. Sie unterscheidet sich von terminalis (auch von Stücken mit reduzierter Basalbinde auf den Flügeldecken) durch die blassere Färbung, die Mikroskulptur des Halsschildes und die reduzierte Sublateral- und Diskalbeborstung der Flügeldecken, von dem ähnlichen puetzi sp. n. durch die Mikroskulptur des Halsschildes, die zahlreichere Apikal- und Lateralbeborstung und die reduzierte Diskalbeborstung der Flügeldecken und den schlankeren Aedoeagus mit unterschiedlicher Innenstruktur.

\section{Tachyporus puetzi sp. n.}

\section{Typenmaterial}

Holotypus: Russia or., Sakhalin, Aniva distr., $5 \mathrm{~km}$ W. Petropavlovsky, tributary of Lyutoga river, 20.-21.VII.1993, Pütz \& Wrase (cSCHÜ). 
Paratypen: gleiche Daten wie der HT, 7 Ex. (cSCHÜ, cPÜTZ); Russia or., Sakhalin, Korsakov distr., 3 km W. Kirilovo vill., Uryun river, 22.-23.VII.1993, leg. Pütz \& Wrase, 4 Ex. (cSCHÜ); Russia or., Sakhalin, Aniva distr., Vysokoye vill., valley of Lyutoga river, 22.23.VII.1993, Pütz \& Wrase, 9 Ex. (cSCHÜ, cPÜTZ); Russia or, Sakhalin, Aniva distr., Novo Alexandrovsk, $10 \mathrm{~km}$ N. Yushne-Sachalinsk, Zazuya river, Pütz \& Wrase, 12.VII.1993, 3 Ex. (c SCHÜ, cPÜTZ); Okr[ug] Baikalskaya, dol. r. Solsan, 18.VI.1978, V. Shilenkov [alles in kyrillischer Schrift], 1 Ex. (MNHUB).

\section{Beschreibung und Differentialdiagnose}

Meßwerte des Holotypus (in mm): Kopfbreite: 0,73; Halsschildbreite: 1,31; Halsschildlänge: 0,84 ; Flügeldeckennahtlänge: 1,02; Flügeldeckenschulterlänge: 1,33 ; Flügeldeckenbreite: 1,27 ; Vorderkörperlänge: 2,40; Gesamtlänge: 4,34; Aedoeaguslänge: 0,92.

Längenverhältnisse der Fühlerglieder 1-11: 8:6,25:7,5:8:8:7,5:7,5:7:7:6,25:11.

Verhältnis Länge/Breite von Fühlerglied 5: 2,46; 7: 1,5; 9: 1,22; 10: 1,04 und 11: 1,69.

Flügeldeckenbeborstung des Holotypus (links/rechts): Humeral: 0/0; Sublateral: 0/0; Diskal (innen): 2/1; Diskal (Mitte): 1/1; Diskal (außen): 0/0; Sutural: 0/0; Apikal: 2/2; Lateral: 3/3.

Färbung: Kopf dunkelbraun bis schwarz, die Stirn über dem Labrum gelb aufgehellt, Labrum und Taster gelb. Halsschild einfarbig gelbrot, nur selten in der Mitte mit einer unscharfen braunen Diskalmakel, Schildchen schwarz, Flügeldecken gelbrot mit schmal geschwärzter Basis (maximal ein Drittel, meist wesentlich weniger als ein Fünftel der Flügeldecken bedeckend). Die Verdunklung reicht an den Seiten der Flügeldecken weiter nach hinten, ist aber nicht so deutlich ausgeprägt wie bei Tachyporus hypnorum oder chrysomelinus. Die Epipleuren werden von der Verdunklung nicht berührt, sie sind einfarbig gelb. Segmente III-VI des Hinterleibes rötlich, Segment VII dunkelbraun bis schwarz mit breit aufgehelltem Hinterrand, ab Segment VIII vollständig dunkelbraun bis schwarz. Beine gelb, die ersten drei bis vier Fühlerglieder gelb, die folgenden in zunehmendem Maße gebräunt.

Kopf klein, die Kopfbreite deutlich geringer als die Halsschildlänge $(0,87)$, die Augen nicht aus dem Kopfumriß hervorragend. Die Oberfläche glänzend mit feiner undeutlicher Punktierung. Fühler gestreckt, auch die vorletzten Glieder noch deutlich länger als breit.

Halsschild quer (Breite : Länge 1,55), Vorderrand breit, die Seitenränder schmal, der Hinterrand nur an den Seiten fein gerandet. An Vorder-, Seiten- und Hinterrand befinden sich die gattungstypischen Borstenreihen aus jeweils vier schwarzen Tastborsten. Vorderecken nach unten gezogen, rechtwinklig kurz abgerundet, Hinterecken sehr breit abgerundet. Die Oberfläche glänzend Schildchen abgerundet dreieckig, vollständig unter dem Halsschild verborgen.

Flügeldecken (Fig. 12) nur wenig länger als breit (Schulterlänge : Breite 1,05), ihre Nahtlänge deutlich größer als die Halsschildlänge $(1,21)$. Flügeldecken mit feiner Grundpunktur (Punktabstand ca. $40 \mu \mathrm{m}$ ), in der eine feine anliegende Grundbehaarung inseriert (Länge der Behaarung ca. $65 \mu \mathrm{m}$ ). Neben der Grundpunktur findet sich eine Flügeldeckenchaetotaxie, die aus zwei Reihen Diskalborstenpunkten, meist zwei Apikalborsten und drei Lateralborsten besteht. Selten kommt auf einer Seite eine Sublateralborste vor. Variabilität der Flügeldeckenchaetotaxie siehe Tabelle. In den Borstenpunkten inserieren kräftige dunkle Tastborsten von etwa $80 \mu \mathrm{m}$ Länge. Hautflügel lang.

Hinterleib wie bei allen Arten der Gattung konisch zugespitzt, die Oberfläche der Segmente in ähnlicher Dichte und Stärke wie die Flügeldecken punktiert und behaart. Segmente an den Seiten mit langen Tastborsten, die Segmente VIII bis X mit zahlreichen langen Tastborsten bis $0,45 \mathrm{~mm}$ Länge. Tergit VII am Hinterrand mit deutlichem Hautsaum zum Falten der Hautflügel. Beine wie bei anderen Arten der Gattung. 


\begin{tabular}{|l|c|c|c|c|c|}
\hline $\mathrm{n}=30$ & 0 Borsten & 1 Borste & 2 Borsten & 3 Borsten & 4 Borsten \\
\hline Humeral & 100 & 0 & 0 & 0 & 0 \\
\hline Sublateral & 93 & 7 & 0 & 0 & 0 \\
\hline Diskal (innen) & 10 & 77 & 13 & 0 & 0 \\
\hline Diskal (Mitte) & 0 & 53 & 47 & 0 & 0 \\
\hline Diskal (außen) & 100 & 0 & 0 & 0 & 0 \\
\hline Sutural & 100 & 0 & 0 & 0 & 0 \\
\hline Apikal & 0 & 0 & 96 & 4 & 0 \\
\hline Lateral & 0 & 3 & 3 & 91 & 3 \\
\hline
\end{tabular}

Tab. 13: Variabilität der Flügeldeckenbeborstung von Tachyporus puetzi sp. n.

Mikroskulptur: Kopf und Halsschild glänzend, ohne sichtbare Mikroskulptur, Flügeldecken mit deutlicher aus queren Linien bestehender Mikroskulptur (2-3 Linien (Maschen)/10 $\mu \mathrm{m}$ ), Hinterleib feiner und enger als die Flügeldecken quermaschig chagriniert (4 Maschen/10 $\mu \mathrm{m}$ ).

Männchen: Vordertarsenglieder 1 und 2 deutlich, Glied 3 kaum erweitert, alle Glieder aber deutlich länger als breit, Mitteltarsen einfach, Sternit VIII am Hinterrand mit abgerundet dreieckigem Ausschnitt, Aedoeagus (Fig. 32) schlank mit deutlicher, schwach sklerotisierter Zentralstruktur und länglichem Basalsklerit.

Weibchen: Vordertarsenglieder 1 und 2 wenig erweitert, Glied 3 kleiner, Tergit VIII am Hinterrand dreifach eingeschnitten und dadurch vier Spitzen bildend, von anderen Arten der Gattung nicht signifikant verschieden.

Derivatio Nominis: Die Art wird einem ihrer Sammler, ANDREAS PÜTZ, Eisenhüttenstadt, gewidmet.

Tachyporus puetzi sieht dem aus Japan beschriebenen Tachyporus frontalis SHARP etwas ähnlich. Da frontalis nach der Originalbeschreibung einen hellen Hinterleib mit etwas dunklerer Spitze besitzt (am Holotypus positiv überprüft) hielt ich die Tiere von Sachalin zuerst für diese Art. Die Überprüfung des Holotypus zeigte aber die Verschiedenheit beider Arten. Tachyporus puetzi unterscheidet sich von frontalis durch das Fehlen von Mikroskulptur auf dem Halsschild, die engere Chagrinierung des Hinterleibes, das Vorhandensein von zwei Reihen Diskalborsten auf den Flügeldecken und die helle Färbung des Hinterleibes, der beim Holotypus von frontalis wahrscheinlich nicht ausgefärbt ist. Aedoeagus schlanker mit unterschiedlichen Innenstrukturen.

\section{Tachyporus suavis SHARP, 1888}

\section{Typenmaterial}

Lectotypus ơ: Tachyporus suavis Type D.S., Fukushima, 28.7.81, Lewis / Type (rund mit rotem Rand) / Japan, G. Lewis, Sharp. Coll. 1905-313 / Lectotypus ơ, Tachyporus suavis Sharp, 1888, des. M. Schülke 1995. Hiermit designiert!

Paralectotypen: Japan, G. Lewis, 1910-320 / Yuyama 10.V.-14.V.81 / 1 Ex. (BMNH); Chiuzenji, 19.VIII.-24.VIII.81 / Japan, G. Lewis, 1910-320 / Tachyporus suavis / 1 Ex. (BMNH); Tachyporus suavis D.S., Nikko, Japan, Lewis / Japan, G. Lewis / Sharp Coll. 1905- 
313 / 1 Ex. (BMNH); Nikko 10.VIII.-18.VIII.81 / Japan, G. Lewis, 1910-320 /Tachyporus suavis var. / 1 Ex. (BMNH). Alle Paralectotypen mit einem Etikett: Paralectotypus Tachyporus suavis Sharp, 1888, des. M. Schülke 1996.

Tachyporus suavis SHARP wurde nach sechs Exemplaren beschrieben. Aus dem BMNH lagen 5 syntypische Exemplare zur Untersuchung vor, ein weiterer Syntypus befindet sich in der Sammlung des FMNH, er wurde nicht untersucht. Da die Art nach mehreren Exemplaren beschrieben wurde, von denen nicht alle untersucht wurden, war die Festlegung eines Lectotypus notwendig. Der Lectotypus ist auf ein Plättchen geklebt und vollständig erhalten.

\section{Weiteres Material}

Japan, Mt. Ichizuchi, Shikoku Isl., 4.6.1952, 5 Ex. (NHMW, cSCHÜ); Japan, Mt. Tahao, leg. Yoshida Wada, 1.6.52, 1 Ex. (cSCHÜ); Sakamoto, Mt. Hiei, Shiga, Japan, 3.5.1994, N. Ito, 1 Ex. (DEI); Japan, Mt. Ishigushi, 6.7.1952, don. Yoshida Wada, 1 Ex. (NHMW).

\section{Ergänzungen zur Beschreibung}

Meßwerte des Lectotypus (in mm): Kopfbreite: 0,73; Halsschildbreite: 1,29; Halsschildlänge: 0,78 ; Flügeldeckennahtlänge: 1,00; Flügeldeckenschulterlänge: 1,15; Flügeldeckenbreite: 1,21 ; Vorderkörperlänge: 2,12; Gesamtlänge: 4,62.

Flügeldeckenbeborstung des Lectotypus (links/rechts): Humeral: 0/0; Sublateral: 1/1; Diskal (innen): 0/0; Diskal (Mitte): 1/1; Diskal (außen): 0/0; Sutural: 0/0; Apikal: 4/4; Lateral: 4/4. Kopf schwarz, Halsschild schwarz mit breit aufgehellten Hinterecken (wie bei Tachyporus suavis Sharp), Flügeldecken dunkelbraun mit undeutlich gelbem Hinterrand, Hinterleib schwarz, Hinterränder der Segmente aufgehellt. Fühler und Beine hell gelb.

Tergit VII am Hinterrand mit einem deutlichen Hautsaum, Fühlerglied 10 länger als breit.

Mikroskulptur: Kopf in der Mitte glatt, die Seiten längsrissig mikroskulpturiert (5 Maschen/ $10 \mu \mathrm{m}$ ), Halsschild quer mikroskulpturiert (3 Maschen/10 $\mu \mathrm{m}$ ). Die Flügeldecken (Fig. 13) mit kräftiger querer Mikroskulptur von 2 Maschen / $10 \mu \mathrm{m}$, der Hinterleib weitläufiger mikroskulpturiert (3 Maschen/10 $\mu \mathrm{m})$.

Aedoeagus (Fig. 21) schlank mit schwach sklerotisierter Zentralstruktur und schlankem, langem Basalsklerit.

\begin{tabular}{|l|c|c|c|c|c|}
\hline $\mathrm{n}=16$ & 0 Borsten & 1 Borste & 2 Borsten & 3 Borsten & 4 Borsten \\
\hline Humeral & 100 & 0 & 0 & 0 & 0 \\
\hline Sublateral & 0 & 100 & 0 & 0 & 0 \\
\hline Diskal (innen) & 100 & 0 & 0 & 0 & 0 \\
\hline Diskal (Mitte) & 0 & 100 & 0 & 0 & 0 \\
\hline Diskal (außen) & 100 & 0 & 0 & 0 & 0 \\
\hline Sutural & 100 & 0 & 0 & 0 & 0 \\
\hline Apikal & 0 & 0 & 0 & 0 & 100 \\
\hline Lateral & 0 & 0 & 0 & 0 & 100 \\
\hline
\end{tabular}

Tab. 14: Variabilität der Flügeldeckenbeborstung von Tachyporus suavis SHARP. 
Tachyporus suavis SHARP sieht dem westpaläarktischen Tachyporus hypnorum (FABRICIUS) äußerlich sehr ähnlich, unterscheidet sich aber in Mikroskulptur und Flügeldeckenbeborstung deutlich. Die Art ist wahrscheinlich mit dem in Südchina verbreiteten Tachyporus flavopictus FAUVEL verwandt.

\section{Tachyporus abdominalis (FABRICIUS, 1781)}

\section{Material}

Nogi, Tochigi, Japan, 3.6.1994, N. Ito, 2 Ex. (DEI, cSCHÜ); Honshu, Kyoto Palace Gdns., 7.-20. VIII.80, P. M. Hammond, 3 Ex. (cSCHÜ), weitere Ex. (BMNH). Russia or., Sakhalin, 1993, Aniva distr., $5 \mathrm{~km} \mathrm{~W}$ Petropavlovskiy, tributary of Lyutoga river, 20.-21.VII., leg. Pütz \& Wrase. 2 Ex. (cSCHÜ); Russia, Sakhalin, Aniva distr., Zunayiskiy Khrebet, Mt. Tshekhov 600-1000 m, 10 km E Novo Alexandrovsk, 13.VII.1993, Pütz \& Wrase, 2 Ex. (cPÜTZ, cSCHÜ); Russia, Sakhalin, Korsakov distr., Ismenshyroye lake, 21./22.VII.1993 Pütz \& Wrase, 2 Ex. (cPÜTZ, cSCHÜ); Russia, Sakhalin, Aniva distr., Vysokoye, valley of Lyutoga river, 22.-23.VII.1993, Pütz \& Wrase, 10 Ex. (cPÜTZ, cSCHÜ).

\section{Beschreibung der Exemplare von Sachalin}

Meßwerte ( $\delta$ von Petropavlovskiy) (in mm): Kopfbreite: 0,65; Halsschildbreite: 1,12; Halsschildlänge: 0,77 ; Flügeldeckennahtlänge: 0,68 ; Flügeldeckenschulterlänge: 0,87 ; Flügeldeckenbreite: 1,10; Vorderkörperlänge: 1,85; Gesamtlänge (ohne Hinterleibsspitze): 3,20; Aedoeaguslänge: 0,82 .

Längenverhältnisse der Fühlerglieder 1-11: 8:5.5:6:5.75:6:5.25:5.25:5:5:4.75:9.

Verhältnis Länge/Breite von Fühlerglied 5: 2,0; 7: 1,31; 9: 1,05; 10: 0,95 und 11: 1,71.

Färbung: Viele der vorliegenden Exemplare sind noch nicht völlig matur. Kopf und Halsschild gelbbraun, bei einigen Exemplaren von Sachalin ist der Kopf dunkelbraun bis schwarz, Halsschild gelbbraun, oft mit einer breiten dunklen Diskalmakel, die nur breite gelbe Seitenränder und einen schmaleren Hinterrand gelb beläßt. Schildchen braun, Flügeldecken einfarbig gelbbraun, Abdomen schwarz, die Hinterränder der Segmente breit aufgehellt, Beine gelbbraun, Labrum gelb, die Taster bis auf die beiden letzten gebräunten Glieder der Kiefertaster gelb, Fühlerglieder 1 und 2 gelb, die anderen Glieder braun.

Kopf mittelgroß, die Kopfbreite deutlich geringer als die Halsschildlänge $(0,91)$, Augen nicht auffällig aus dem Kopfumriß hervortretend. Oberfläche glänzend mit äußerst feiner und weitläufiger Mikropunktur, ohne sichtbare Behaarung. Fühler relativ kräftig, die vorletzten Glieder etwa so breit wie lang.

Halsschild quer (Breite : Länge 1,56), Vorderrand und Seitenränder deutlich gerandet, der Hinterrand ohne sichtbare Randung. Vorderecken nach unten umgebogen, rechteckig kurz abgerundet, Hinterecken völlig abgerundet. An Vorder-, Seiten- und Hinterrand befinden sich jeweils vier kräftige Borstenpunkte, in denen kräftige abstehende Tastborsten inserieren. Oberfläche des Halsschildes glänzend, mit verloschener Mikropunktur wie auf dem Kopf, ohne sichtbare Behaarung. Schildchen abgerundet dreieckig.

Flügeldecken (Fig. 14) kurz, deutlich breiter als lang (Schulterlänge : Breite 0,79), ihre Nahtlänge kürzer als die Halsschildlänge $(0,88)$. Flügeldecken mit feiner Grundpunktur (Punktabstand ca. $40 \mu \mathrm{m}$ ), in der eine feine anliegende Grundbehaarung inseriert (Länge der Behaarung ca. $60 \mu \mathrm{m}$ ). Neben der Grundbehaarung befinden sich auf den Flügeldecken eine Diskalborstenpunktreihe, meist zwei Suturalborstenpunkte, drei Apikal- und drei bis vier Lateralborstenpunkte, in denen bis $120 \mu \mathrm{m}$ lange kräftige und abstehende Tastborsten inserieren. Variabilität der Flügeldeckenchaetotaxie siehe Tabelle. Hautflügel meist reduziert, kürzer als die Flügeldecken, selten länger als die Flügeldecken. 


\begin{tabular}{|l|c|c|c|c|c|}
\hline $\mathrm{n}=59$ & 0 Borsten & 1 Borste & 2 Borsten & 3 Borsten & 4 Borsten \\
\hline Humeral & 100 & 0 & 0 & 0 & 0 \\
\hline Sublateral & 7 & 93 & 0 & 0 & 0 \\
\hline Diskal (innen) & 100 & 0 & 0 & 0 & 0 \\
\hline Diskal (Mitte) & 0 & 3 & 66 & 31 & 0 \\
\hline Diskal (außen) & 100 & 0 & 0 & 0 & 0 \\
\hline Sutural & 0 & 32 & 68 & 0 & 0 \\
\hline Apikal & 0 & 0 & 0 & 100 & 0 \\
\hline Lateral & 0 & 0 & 0 & 25 & 75 \\
\hline
\end{tabular}

Tab. 15: Variabilität der Flügeldeckenbeborstung von Tachyporus abdominalis (FABRICIUS) (nur Material aus Japan und Sachalin).

Hinterleib nach hinten konisch zugespitzt, die Oberfläche in gleicher Weise wie die Flügeldecken punktiert und fein anliegend behaart. Segmente III-VII an den Seiten mit langen kräftigen Tastborsten, die Segmente VIII bis X besonders am Hinterrand mit zahlreichen langen Tastborsten versehen (bis $0,45 \mathrm{~mm}$ Länge). Tergit VII mit deutlichem Hautsaum. Beine wie bei den anderen Arten der Gattung gebildet.

Mikroskulptur: Die Angaben zur Mikroskulptur dieser Art bei CAMPBELL (1979) sind falsch! Kopf und Halsschild glänzend, ohne sichtbare Mikroskulptur, Flügeldecken kräftig und weitläufig querlinig chagriniert (1,5-2 Maschen/10 $\mu \mathrm{m})$, Hinterleib ebenfalls deutlich, aber enger quermaschig chagriniert (ca. 3 Maschen/10 $\mu \mathrm{m}$ ).

Männchen: Vordertarsenglieder 1 bis 3 erweitert, Mitteltarsenglieder 1 bis 3 ebenfalls etwas erweitert, Sternit VIII am Hinterrand mit einem abgerundet dreieckigen Mittelausschnitt, Aedoeagus (Fig. 33, 34) schlank mit zentralen Borstenfeldern und kleinem Basalsklerit mit charakteristischer hakenförmig umgebogenem Basalende.

Weibchen: Vordertarsen kaum erweitert, Tergit VIII mit drei tiefen Einschnitten, vierzipfelig.

Tachyporus abdominalis ist in der nördlichen Holarktis weit verbreitet. Aus Japan wurde die Art bisher nicht gemeldet. Vom ostasiatischen Festland liegen Belege aus Primorie, dem Gebiet von Chabarovsk und von Kamtschatka vor (SCHÜLKE, 1995). Typen von abdominalis wurden bisher nicht untersucht, dies war im Zusammenhang mit dieser Arbeit auch nicht notwendig. Die aus Sachalin vorliegenden Tiere machten durch ihre dunkle Färbung zunächst den Eindruck einer eigenen Art. Die Untersuchung der Flügeldeckenbeborstung, der Mikroskulptur und der Innenstrukturen des Aedoeagus zeigte jedoch keine verwertbaren Unterschiede. Das Basalsklerit europäischer abdominalis zeigt die selbe Form wie bei den von Sachalin vorliegenden Stücken.

\section{Weitere Arten}

Von Sachalin liegen einzelne Weibchen zweier weiterer, bisher nicht sicher zuzuordnender Arten vor. Zum einen handelt es sich um drei Weibchen, die Tachyporus obscurellus ZETTERSTEDT ähnlich sehen, sich von europäischem und sibirischem Material dieser Art durch eine kräftigere und engere Mikroskulptur auf den Flügeldecken unterscheiden. Ein Vorkommen von 
obscurellus auf Sachalin wäre aus zoogeographischen Gründen nicht auszuschließen. Ob die vorliegenden Tiere zu obscurellus gehören, kann nur anhand der Genitalmorphologie festgestellt werden.

Von Novo Alexandrovsk liegt ein Weibchen einer weiteren Art vor, die durch Färbung, Mikroskulptur und Flügeldeckenbeborstung an Tachyporus pulchellus MANNERHEIM erinnert, aber sicher nicht mit diesem identisch ist. Möglicherweise ist diese Art mit Tachyporus celatus var. longipennis BERNHAUER, 1927 identisch, dessen Type ich bisher noch nicht untersuchen konnte.

\section{Zwei neue Arten der Tachyporus ruficollis-Gruppe aus dem Fernen Osten Rußlands}

\section{Tachyporus ussuriensis sp. $\mathrm{n}$.}

\section{Typenmaterial}

Holotypus - ठ̊: Russia, Prim., Partizansk distr., Alexeyevsky Khreb., 20 km E Sergeyevka, S. env. Mt. Olkhovaya, 800-1200m, 27.VII.1993, Pütz \& Wrase; Holotypus, Tachyporus ussuriensis nov. spec., M. Schülke det. 1995 (cSCHÜ).

Paratypen: gleiche Daten wie der Holotypus, 1 Ex. (cPÜTZ); Ussuri - Gebiet, Partisanskij Rajon, 20.VII.1993, leg. J. Sundukov, chr. Aleksejewka, Mt. Olchowaja, 1500-1550 m, WaldTundra-Grenze (MNHUB).

Aus dem Ussuri-Gebiet im äußersten Osten Rußlands lagen mir bisher 3 Exemplare eines Tachyporus vor, die dem mitteleuropäischen Tachyporus ruficollis GRAVENHORST sehr ähnlich sehen. Die Art unterscheidet sich von $T$. ruficollis jedoch durch geringfügige, nach dem vorliegenden Material aber konstante Unterschiede in der Ausbildung der männlichen Geschlechtsmerkmale und der Färbung. Da beide Formen obligatorisch flugunfähig sind und durch eine mehr als 5000 Kilometer breite Verbreitungslücke getrennt sind, betrachte ich sie als getrennte Arten und beschreibe die ostsibirische Form als Tachyporus ussuriensis $\mathrm{sp}$. n. Beide Formen sind Schwesternarten, wie neben der habituellen Ähnlichkeit (die auch japanische Arten wie Tachyporus orthogrammus oder T. oculatus besitzen) besonders die Reduktion der Flügeldeckenbeborstung beider Arten beweist. Bei beiden Arten sind die Humeral- und Sublateralborsten völlig reduziert, Diskalborsten kommen normalerweise nur in einer Reihe vor. Bemerkenswerterweise fand sich in Material aus der Provinz Chabarovsk eine äußerlich und in der Flügeldeckenbeborstung sehr ähnliche weitere Art, die sich jedoch durch deutliche Unterschiede im Bau des Aedoeagus von ruficollis und ussuriensis unterscheidet.

\section{Beschreibung und Differentialdiagnose}

Tachyporus ussuriensis sp. n. ist Tachyporus ruficollis so ähnlich, daß hier nur die Angabe der Unterschiede sinnvoll ist.

Kopf schwarz, Halsschild gelbrot, Flügeldecken einfarbig rötlich, Hinterleib schwarz mit hellen Hinterrändern der Segmente, Beine und Mundteile gelb, Fühler einfarbig gelbbraun, etwas dunkler als die Beine. Meßwerte des Holotypus (in mm): Kopfbreite 0,74; Halsschildbreite 1,22; Halsschildlänge 0,78 ; Flügeldeckennahtlänge 0,68 ; Flügeldeckenschulterlänge 0,90 ; Flügeldeckenbreite 1,20; Vorderkörperlänge 2,03; Gesamtlänge (ohne Hinterleibsspitze) 3,75; Länge des Aedoeagus 0,91. Längenverhältnisse der Fühlerglieder 1-11: 8:6:6,5:6,25:7:6,75: 6,25:6:6:5,75:9; Längen/Breitenverhältnisse der Fühlerglieder: Glied 5: 6,5:3; Glied 9: 6:4,5; Glied 10: 5,75:5.

Flügeldeckenbeborstung des Holotypus (links/rechts): Humeral: 0/0; Sublateral: 0/0; Diskal (innen): 0/0; Diskal (Mitte): 2/2; Diskal (außen): 0/0; Sutural: 2/2; Apikal: 4/4; Lateral: 4/3. 
Kopf groß, fast so breit wie die Halsschildlänge (Holotypus: 0,95:1), Halsschild quer (Holotypus: 1,56:1), etwa so breit wie die Flügeldecken. Flügeldecken (Fig. 15) kurz, ihre Nahtlänge kürzer als die Halsschildlänge (Holotypus: $0,87: 1$ ) und zusammen um ein Drittel breiter als lang (Holotypus: Flügeldeckenbreite : Schulterlänge 1,33:1). Flügeldeckenbeborstung wie bei Tachyporus ruficollis GRAVENHORST ohne Humeral- und Sublateralborsten und mit nur einer Reihe Diskalborsten, in der Variabilität von ruficollis liegend. Hautflügel bis auf kleine Reste reduziert. Tergit VII ohne Hautsaum am Hinterrand. Kopf und Halsschild glatt, ohne Mikroskulptur, Flügeldecken mit kräftigem und weitläufigem querwelligen Chagrin (ca. 2 Maschen/10 $\mu \mathrm{m}$ ), Hinterleib ebenfalls kräftig, aber dichter als die Flügeldecken querwellig chagriniert.

\begin{tabular}{|l|c|c|c|c|c|c|}
\hline $\mathrm{n}=6$ & 0 Borsten & 1 Borste & 2 Borsten & 3 Borsten & 4 Borsten & 5 Borsten \\
\hline Humeral & 100 & 0 & 0 & 0 & 0 & 0 \\
\hline Sublateral & 100 & 0 & 0 & 0 & 0 & 0 \\
\hline Diskal (innen) & 100 & 0 & 0 & 0 & 0 & 0 \\
\hline Diskal (Mitte) & 0 & 0 & 83 & 17 & 0 & 0 \\
\hline Diskal (außen) & 100 & 0 & 0 & 0 & 0 & 0 \\
\hline Sutural & 0 & 0 & 100 & 0 & 0 & 0 \\
\hline Apikal & 0 & 0 & 0 & 0 & 83 & 17 \\
\hline Lateral & 0 & 0 & 0 & 50 & 33 & 17 \\
\hline
\end{tabular}

Tab. 16: Variabilität der Flügeldeckenbeborstung von Tachyporus ussuriensis sp. $\mathrm{n}$.

Männchen: Vordertarsen kräftig erweitert. Sternit VIII mit kräftigem Mittelausschnitt. Aedoeagus kräftig (Fig. 35-36), mit deutlichen, schwach sklerotisierten Zentralstrukturen und gebogenem Basalsklerit.

Derivatio Nominis: Der Name der Art wird ihrer geographischen Verbreitung im Ussuri-Gebiet Rußlands entlehnt.

Geographische Verbreitung: Bisher nur vom Mt. Olkhovaja im Ussuri-Gebiet Rußlands bekannt.

Tachyporus ussuriensis unterscheidet sich von Tachyporus ruficollis durch die gleichmäßig helle Färbung der Flügeldecken, das kleinere Sternit VIII des Männchens mit einem flacheren und breiteren Mittelausschnitt. Aedoeagus etwas schmaler, die Parameren an der Spitze etwas verlängert. Von Tachyporus zerchei sp. n. unterscheidet sich ussuriensis durch die hellere Färbung von Halsschild und Flügeldecken und den Bau des Aedoeagus, besonders die Form des Basalsklerits. Von allen anderen bekannten Arten der atriceps-Gruppe unterscheidet sie sich durch die reduzierte Flügeldeckenbeborstung.

\section{Tachyporus zerchei sp. $\mathrm{n}$.}

\section{Typenmaterial}

Holotypus: Russia: Khabarovskiy Kray, Boitsovo, $10 \mathrm{~km}$ N Bikin, Shivki Mtn., 47.05 N, 134.18 E, 27.V.1993, 200 m, leg. L. Zerche, 1 Ex. (DEI). 
Paratypus: Russia: Khabarovskiy Kray, Boitsovo, $20 \mathrm{~km} \mathrm{~N}$ Bikin, Bolshoi Solntsepyok Hill, 47.02 N, 134.21 E, 26.V.1993, 250 m, leg. L. Zerche, 1 Ex. (cSCHÜ) .

\section{Beschreibung und Differentiall diagnose}

Meßwerte des Holotypus (in mm): Kopfbreite: 0,65; Halsschildbreite: 1,04; Halsschildlänge: 0,70 ; Flügeldeckennahtlänge: 0,62 ; Flügeldeckenschulterlänge: 0,83 ; Flügeldeckenbreite: 1,12 ; Vorderkörperlänge: 1,78; Gesamtlänge: 3,32; Aedoeaguslänge: 0,90.

Längenverhältnisse der Fühlerglieder 1-11: 9:5.5:5:5:5.25:5:5:4.75:4.5:4.5:8.25

Verhältnis Länge/Breite von Fühlerglied 5: 1.91; 7: 1.25; 9: 1.12; 10: 1.06 und 11: 1.83.

Flügeldeckenbeborstung des Holotypus (links/rechts): Humeral: 0/0; Sublateral: 0/0; Diskal (innen): 0/0; Diskal (Mitte): 2/2; Diskal (außen): 0/0; Sutural: 1/1; Apikal: 4/4; Lateral: 3/3.

Färbung: Kopf schwarz, Halsschild in der Vorderhälfte schwarz, die dunkle Färbung in der Mitte weiter nach hinten reichend, Basis dunkel gelbbraun, Schildchen schwarz, Flügeldecken schwarz mit gelbbraunem Hinterrand, Abdomen schwarz mit undeutlich aufgehellten Hinterrändern der Segmente III-VII, Hinterleibsspitze schwarzbraun, Beine gelbbraun, die Tarsen des mittleren und hinteren Beinpaares dunkler braun. Labrum dunkelbraun mit helleren Vorderrand, Taster gelbbraun, die letzten zwei Glieder der Kiefertaster braun, Fühlerbasis (Glieder 1 bis 4) gelb, die folgenden Glieder in zunehmenden Maße angedunkelt.

Kopf breit, die Kopfbreite aber etwas schmaler als die Halsschildlänge (0,93 beim Holotypus), die Augen groß, nur wenig aus dem Kopfumriß hervortretend. Oberfläche des Kopfes glänzend mit feiner sehr weitläufiger Mikropunktur, in der feine, tomentartige Haare von nur $15 \mu \mathrm{m}$ Länge inserieren (meist abgeschabt). Fühler gestreckt, die vorletzten Glieder wenig länger als breit. Halsschild quer (Breite : Länge 1,49), Vorderrand und Seitenränder kräftig, der Hinterrand nur in den Hinterecken fein gerandet. An Vorder-, Seiten- und Hinterrand befinden sich jeweils vier gattungstypische Borstenpunkte, in denen kräftige abstehende Tastborsten inserieren. Vorderecken nach unten gezogen, rechteckig kurz abgerundet, die Hinterecken völlig verrundet. Oberfläche des Halsschildes glänzend, in gleicher Weise wie der Kopf mikroskopisch fein und weitläufig punktiert und fein behaart. Schildchen abgerundet dreieckig, vollständig unter dem Halsschild verborgen.

\begin{tabular}{|l|c|c|c|c|c|c|}
\hline $\mathrm{n}=4$ & 0 Borsten & 1 Borste & 2 Borsten & 3 Borsten & 4 Borsten & 5 Borsten \\
\hline Humeral & 100 & 0 & 0 & 0 & 0 & 0 \\
\hline Sublateral & 100 & 0 & 0 & 0 & 0 & 0 \\
\hline Diskal (innen) & 100 & 0 & 0 & 0 & 0 & 0 \\
\hline Diskal (Mitte) & 0 & 25 & 75 & 0 & 0 & 0 \\
\hline Diskal (außen) & 100 & 0 & 0 & 0 & 0 & 0 \\
\hline Sutural & 0 & 75 & 25 & 0 & 0 & 0 \\
\hline Apikal & 0 & 0 & 0 & 0 & 100 & 0 \\
\hline Lateral & 0 & 0 & 0 & 75 & 25 & 0 \\
\hline
\end{tabular}

Tab. 17: Variabilität der Flügeldeckenbeborstung von Tachyporus zerchei sp. n. 
Flügeldecken (Fig. 16) kurz, viel kürzer als zusammen breit (Schulterlänge : Breite 0,75), ihre Nahtlänge kürzer als die Halsschildlänge $(0,88$ beim Holotypus). Flügeldecken mit feiner Grundpunktur (Punktabstand ca. 30-35 $\mu \mathrm{m}$ ), in der eine feine anliegende Behaarung von ca. $50 \mu \mathrm{m}$ Länge inseriert. Neben der Grundpunktur befinden sich auf jeder Flügeldecke eine Diskalborstenpunktreihe mit ein bis zwei Borstenpunkten, meist vier Apikal- und drei Lateralborstenpunkten. Humeral-, Sublateral- und Suturalborstenpunkte sind nicht vorhanden.

In den Borstenpunkten inserieren wie in den Borstenpunkten am Halsschild-Seitenrand kräftige abstehende Tastborsten von ca. $100 \mu \mathrm{m}$ Länge. Hautflügel reduziert, kürzer als die Flügeldecken.

Hinterleib wie bei allen Arten der Gattung nach hinten konisch zugespitzt, die Oberfläche der Segmente in gleicher Weise wie die Flügeldecken mit einer feinen Grundpunktur und anliegender Behaarung versehen. Segmente an den Seiten mit sehr langen und kräftigen Tastborsten, die Hinterleibsspitze mit zahlreichen Tastborsten von bis zu $0,4 \mathrm{~mm}$ Länge versehen. Tergit VII ohne Hautsaum am Hinterrand. Beine wie bei den anderen Arten der Gattung gebildet.

Mikroskulptur: Kopf und Halsschild glatt und ohne Mikroskulptur, Flügeldecken mit kräftiger querliniger Chagrinierung von ca. 2-3 Maschen/10 $\mu \mathrm{m}$, Hinterleib feiner als die Flügeldecken mikroskulpturiert (ca. 4 Maschen/10 $\mu \mathrm{m}$ ).

Männchen: Vordertarsenglieder 1 bis 3 deutlich erweitert, Mitteltarsen einfach, Sternit VIII am Hinterrand mit deutlichem Mitteleinschnitt, Aedoeagus (Fig. 37) kräftig mit kräftigen Parameren, deutlich schwach sklerotisierten Zentralstrukturen und kurzem kräftigen Basalsklerit.

Weibchen: Vordertarsen einfach, Glied 2 viel länger als 1 und 3, Tergit VIII am Hinterrand mit drei tiefen Einschnitten, vierzipfelig.

Bionomie: Beide Tiere wurden an Laubwaldstandorten gesiebt.

Derivatio Nominis: Die Art wird dem Sammler der Art, dem Staphyliniden-Spezialisten Lothar Zerche, Eberswalde, gewidmet.

Tachyporus zerchei unterscheidet sich von ussuriensis durch die dunkle Färbung der Flügeldecken und des Halsschildes und durch die Form des Basalsklerits im Aedoeagus, von ruficollis durch den angedunkelten Halsschild und die kräftigen Innenstrukturen des Aedoeagus, besonders durch den Bau des Basalsklerits, von allen anderen Arten der atriceps-Gruppe durch die reduzierte Beborstung der Flügeldecken.

\section{Bestimmungstabelle der bisher vom japanischen Archipel und von Sachalin bekannten Tachyporus-Arten}

1 Arten mit großem breitem Kopf, das Verhältnis Kopfbreite zu Halsschildlänge meist 1,0 oder größer, Arten mit kurzen bis sehr kurzen Flügeldecken . . . . . . . . . 2

1* Arten mit kleinerem, schmalerem Kopf, das Verhältnis Kopfbreite zu Halsschildlänge meist 0,9 oder kleiner, selten bis 0,95, dann Arten mit nicht sehr kurzen Flügeldecken

2 Auf den Flügeldecken befindet sich kein Sublateralborstenpunkt, einfarbig dunkle Art mit sehr kurzen Flügeldecken. Japan (Honshu) . . . . . . . . . . oculatus SHARP

2* Auf den Flügeldecken befindet sich mindestens ein Sublateralborstenpunkt, einfarbig dunkel oder mit gelber Zeichnung auf den dunklen Flügeldecken . . . . . . . . . 3

3 Flügeldecken sehr kurz und einfarbig dunkelbraun bis schwarz. Japan (Honshu, Shikoku)

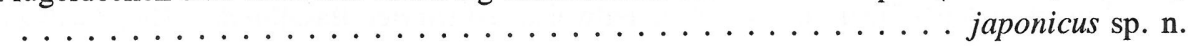

3* Flügeldecken etwas bis deutlich länger, dunkelbraun bis schwarz mit gelbem Hinterrand und einer gelben von den Schultern ausgehenden Längsbinde . . . . . . . . . . 4 
4 Halsschild dunkel mit schmalem hellen Rand, Flügeldecken länger, ihre Nahtlänge deutlich größer als die Halsschildlänge, mit zwei Diskalborstenreihen, Hinterrand des Tergit VII mit deutlichem Hautsaum. Japan (Honshu, Shikoku) . . . . . orthogrammus SHARP

4* Halsschild hell mit dunkler Diskalmakel, Flügeldecken kürzer, ihre Nahtlänge kürzer als die Halsschildlänge, Flügeldecken mit drei Reihen Diskalborsten, Hinterrand von Tergit VII ohne Hautsaum. Japan (Honshu) . . . . . . . . . . . cephalotes $\mathrm{sp.} \mathrm{n}$.

5 Flügeldecken mit zahlreicher Beborstung, mit Humeral- und Sublateralborstenpunkten und mindestens zwei Reihen Diskalborstenpunkten . . . . . . . . . . . . . 6

5* Flügeldecken weniger zahlreich beborstet, ohne Humeral- oder Sublateralborstenpunkt, oft nur mit einer Reihe Diskalborstenpunkten . . . . . . . . . . . . . . 7

6 Dunkel gefärbte Art, Kopf und Halsschild schwarz, Flügeldecken dunkelbraun bis schwarz mit auffälliger $\mathrm{x}$-förmiger gelber Zeichnung. Flügeldecken mit zwei Reihen Diskalborstenpunkten. Japan (Honshu) . . . . . . . . . . . klapperichi SCHÜLKE

6* Heller gefärbte Art, Halsschild heller, Flügeldecken bräunlich, variabel, aber weniger kontrastreich gefärbt. Flügeldecken meist mit drei Reihen Diskalborsten. Japan (Kyushu, Honshu, Hokkaido) und auf dem ostasiatischen Festland. Sicher auch auf Shikoku und

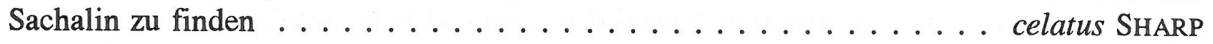

7 Flügeldecken ohne Humeral-, Sublateral- und Suturalborstenpunkte . . . . . . . . 8 8

7* Flügeldecken mit Sublateralborstenpunkt/en, mit oder ohne Humeral- und Sutural-

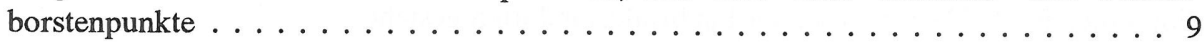

8 Körper kleiner, Diskalmakel auf dem Halsschild deutlicher. Halsschild deutlich chagriniert. Flügeldecken mit nur einem Diskalborstenpunkt. Japan (Honshu) . . . . . . . . . Körper größer und etwas abgeflacht, Diskalmakel auf dem Halsschild undeutlicher. Halsschild ohne Chagrin, Flügeldecken meist mit zwei Reihen Diskalborstenpunkten.

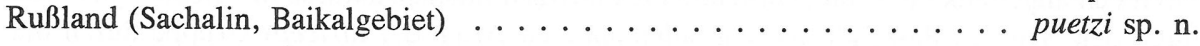

9 Halsschild deutlich chagriniert. Große dunkel gefärbte Art mit hellen Halsschild-Hinterecken und hellem Hinterrand der Flügeldecken. Japan (Kyushu, Shikoku und Honshu)

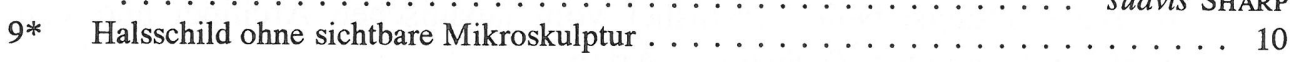

10 Flügeldecken glatt, ohne sichtbare Mikroskulptur. Kopf schwarz, Halsschild und Flügeldecken einfarbig hell. Japan (Honshu) . . . . . . . . . celatoides $\mathrm{sp.} \mathrm{n}$.

10* Flügeldecken wenigstens in der Hinterhälfte mit deutlichem Chagrin, oft dunkler gefärbte

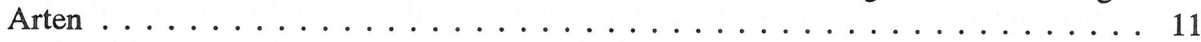

11 Flügeldecken kurz, mit nur einer Reihe Diskalborstenpunkten. Kopf, Halsschild und Flügeldecken hell gelbrot (Festland: Sibirien, Primorie, Kamtschatka; Japan: Honshu)) oder Kopf und Halsschild angedunkelt (Sachalin), Basis des Hinterleibs dunkel . . . .

11* Flügeldecken länger, mit mehreren Reihen Diskalborstenpunkten oder Flügeldecken ähnlich kurz, dann aber auffällig zweifarbige Tiere mit heller Basis des Hinterleibs

12 Flügeldecken kürzer mit dunkler, teilweise reduzierter Basalbinde. Flügeldeckenbeborstung weniger umfangreich, meist mit nur einem inneren Diskalborstenpunkt. Japan (Honshu, Hokkaido), Rußland (Sachalin, Ferner Osten, Altai), China (Mandschurei) 
12* Flügeldecken etwas länger, Skutellarregion und Seitenrand dunkel, Halsschild oft mit Diskalmakel. Flügeldecken mit zwei Reihen Diskalborstenpunkten . . . . . . . . . 13

13 Halsschild mit schmalem länglichem Diskalfleck. Flügeldecken mit Suturalborstenpunkten. Aedoeagus mit schmaler Zentralstruktur und typischem Sklerit. Westpaläarktis, Sibirien,

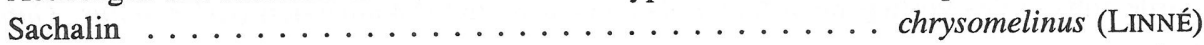

13* Halsschild mit breitem Diskalfleck. Flügeldecken meist ohne Suturalborstenpunkte. Aedoeagus mit breiter Zentralstruktur und langem Sklerit. Rußland (Sachalin) . . . . . .

\section{Zur Zoogeographie der Tachyporus Japans und Sachalins}

\subsection{Japan}

Die Tachyporus-Fauna Japans ist durch einen hohen Grad an Endemismus gekennzeichnet. Nur vier der elf aus Japan nachgewiesenen Arten kommen auf dem ostasiatischen Festland vor, ebenfalls nur vier Arten sind bisher von mehreren der japanischen Hauptinseln sicher nachgewiesen (siehe Tabelle 18).

\begin{tabular}{|c|c|c|c|c|c|c|}
\hline Art & Kyushu & Shikoku & Honshu & Hokkaido & Sachalin & Festland \\
\hline abdominalis & & & $\mathrm{x}$ & & $\mathrm{x}$ & $\mathrm{x}$ \\
\hline celatoides & & & $\mathrm{x}$ & & & \\
\hline celatus & $\mathrm{x}$ & & $\mathrm{x}$ & $\mathrm{x}$ & & $\mathrm{x}$ \\
\hline cephalotes & & & $\mathrm{x}$ & & & \\
\hline frontalis & & & $\mathrm{x}$ & & & \\
\hline japonicus & & $\mathrm{x}$ & $\mathrm{x}$ & & & \\
\hline klapperichi & & & $\mathrm{x}$ & & & $\mathrm{x}$ \\
\hline oculatus & & & $\mathrm{x}$ & & & \\
\hline orthogrammus & & $\mathrm{x}$ & $\mathrm{x}$ & & & \\
\hline puetzi & & & & & $\mathrm{x}$ & $\mathrm{x}$ \\
\hline chrysomelinus & & & & & $\mathrm{x}$ & $\mathrm{x}$ \\
\hline suavis & $\mathrm{x}$ & $\mathrm{x}$ & $\mathrm{x}$ & & & \\
\hline terminalis & & & $\mathrm{x}$ & $\mathrm{x}$ & $\mathrm{x}$ & $\mathrm{x}$ \\
\hline wrasei & & & & & $\mathrm{x}$ & \\
\hline spec. cf. obscurellus & & & & & $\mathrm{x}$ & $?$ \\
\hline spec. cf. pulchellus & & & & & $\mathrm{x}$ & $?$ \\
\hline Summe & 2 & 3 & 11 & 2 & 7 & \\
\hline
\end{tabular}

Tab. 18: Verbreitung von Tachyporus-Arten in Japan, auf Sachalin und auf dem ostasiatischen Festland. 
Ein solch hoher Grad an Endemismus ist für die japanische Fauna typisch und auch in anderen jüngst revidierten Staphylinidengruppen vorhanden (siehe Tabelle 19). Die zum Vergleich verwendeten Taxa wurden sowohl für Japan als auch für die kontinentale Ostpaläarktis revidiert (Tachinus, Megarthrus, Coryphiini) bzw. das Vorkommen japanischer Arten auf dem Festland wurde anhand des vorliegenden Materials untersucht und dokumentiert (Erichsonius, Gabrius).

\begin{tabular}{|l|l|c|c|c|}
\hline Taxon & Autoren & $\begin{array}{c}\text { Artenzahl } \\
\text { Japan }\end{array}$ & Endemisch & $\begin{array}{c}\text { Endemisch } \\
(\%)\end{array}$ \\
\hline Tachinus & $\begin{array}{l}\text { ULLRICH (1975), LI (1984, 1985a, } \\
\text { 1985b), VESELOVA (1990) }\end{array}$ & 20 & 15 & 75 \\
\hline Megarthrus & $\begin{array}{l}\text { CUCCODORO (1996), CUCCODORO \& } \\
\text { LÖBL (1997) }\end{array}$ & 16 & 11 & 69 \\
\hline Gabrius & $\begin{array}{l}\text { SMETANA (1984a, 1984b), SHIBATA } \\
\text { (1991) }\end{array}$ & 17 & 15 & 88 \\
\hline Erichsonius & UHLIG \& WATANABE (1992) & 10 & 10 & 100 \\
\hline Coryphiini & ZERCHE (1990, 1993) & 14 & 12 & 86 \\
\hline Tachyporus & & 11 & 7 & 64 \\
\hline
\end{tabular}

Tab. 19: Vergleich der Endemitenrate bei verschiedenen japanischen Staphylinidentaxa.

\begin{tabular}{|l|c|c|c|c|c|c|c|}
\hline Taxon & $\begin{array}{c}\text { Artenzahl } \\
\text { Japan }\end{array}$ & $\begin{array}{c}\text { Kyushu u. } \\
\text { Ryu Kiu } \\
\text { Isl. }\end{array}$ & Shikoku & Honshu & Hokkaido & $\begin{array}{c}\text { auf } \\
\text { mehreren } \\
\text { Inseln }\end{array}$ & in \% \\
\hline Tachinus & 20 & 7 & 12 & 14 & 9 & 12 & 60 \\
\hline Megarthrus & 16 & 3 & 9 & 15 & 2 & 9 & 56 \\
\hline Gabrius & 17 & 3 & 3 & 17 & 1 & 7 & 41 \\
\hline Erichsonius & 10 & 3 & 2 & 8 & 4 & 4 & 40 \\
\hline Coryphiini & 14 & 2 & 1 & 12 & 4 & 4 & 29 \\
\hline Tachyporus & 11 & 2 & 3 & 11 & 1 & 4 & 36 \\
\hline
\end{tabular}

Tab. 20: Vergleich der Rate an Inselendemiten bei verschiedenen japanischen Staphylinidentaxa.

UlLRICH (1975) diskutiert für die Gattung Tachinus eine zwei- oder dreimalige Besiedlung Japans durch Tachinus aus der östlichen Paläarktis über durch eustatische Absenkungen des Meeresspiegels während der pleistozänen Kaltzeiten entstandene Landbrücken. Dabei werden die heute in Japan und auf dem Festland vorkommenden Arten als Besiedler während der letzten Landverbindung (entsprechend der europäischen Weichsel/Würm-Vereisung) postuliert, während die Vorfahren der endemischen Arten bereits während der Saale/Riß-Vereisung oder der Elster/ 
Mindel-Vereisung nach Japan eingewandert sind. Für die Vorfahren von Tachinus nakanei ULLRICH (für den die monotypische Untergattung Japanotachinus aufgestellt wird) wird bereits eine Besiedlung im Jungtertiär angenommen. Das letzte Beispiel zeigt, daß unsere Vorstellungen der Faunengeschichte oft von mangelnder Materialbasis beeinflußt wird. Eine Tachinus nakanei sehr ähnliche Art wurde inzwischen im südlichen China (Sichuan, Emei-Shan) gefunden, die Untergattung Japanotachinus ist damit nicht in Japan endemisch. Eine sehr frühe Besiedlung Japans durch Tachinus nakanei oder dessen Vorfahren ist damit nicht zwingend.

Über die Besiedelung Japans durch Tachyporus lassen sich meiner Meinung nach derzeit keine schlüssigen zeitlichen Angaben machen. Keine der aus Japan bisher bekannten Arten gehört zur orealen Fauna der Japanischen Hochgebirge, für die eine lange endemische Entwicklung vorauszusetzen wäre oder zu einer nur in Japan vorkommenden Artengruppe. Ungeflügelte Gebirgsbewohner sind nur Tachyporus oculatus, japonicus und cephalotes, alle gehören zur atriceps-Gruppe. Konkrete Höhenangaben für Fundorte liegen kaum vor, Tachyporus japonicus wurde auf Shikoku in 1400 m Höhe gefunden, Tachyporus cephalotes auf Honshu in nur 700 m Höhe. Diese Fundorte liegen alle noch in der Laubmischwaldstufe der japanischen Gebirge (KLOTZ, 1989).

Besser als die zeitliche Abfolge der Besiedlung Japans durch Tachyporus läßt sich die räumliche Herkunft der meisten japanischen Tachyporus bestimmen. Die meisten japanischen Tachyporus gehören zu Artengruppen, die in der östlichen Paläarktis weit verbreitet sind. Fünf Arten (orthogrammus, oculatus, japonicus, cephalotes und klapperichi) gehören zur Tachyporus atricepsGruppe, die in Ostasien zwischen der Region von Chabarovsk im russischen Amurgebiet bis nach Taiwan und Fukien im Süden und bis nach Kansu und Sichuan im Westen besonders montan verbreitet ist. Die nächsten bekannten Verwandten der japanischen Arten leben in China, teilweise in Fukien und auf Taiwan. Die beiden bisher in Rußland (Primorski Kraj, Chabarovski Kraj) gefundenen Arten sind nicht näher mit den japanischen Vertretern der Artgruppe verwandt, so daß die Einwanderung der japanischen Arten bzw. ihrer Vorfahren über eine nördliche Landbrücke unwahrscheinlich ist. Die japanischen Vertreter der Artengruppe wurden bisher von Shikoku und aus dem südlichen Teil Honshus bekannt.

Zwei Arten, der weit verbreitete Tachyporus celatus und der in Japan endemische T. celatoides, gehören zur chrysomelinus-Gruppe im weiteren Sinne. Die Artengruppe ist über die Paläarktis weit verbreitet und kommt auch in der Nearktis vor. Arten der chrysomelinus- Gruppe kommen auch auf Sachalin vor, was eine Einwanderung der betreffenden Arten von Norden her wahrscheinlich macht.

Tachyporus terminalis und frontalis gehören in die Verwandtschaft der westpaläarktischen Arten Tachyporus obtusus, formosus und solutus. Da terminalis auf Sachalin und dem Festland in der nördlichen Mandschurei und im fernen Osten Rußlands vorkommt und der nächste Verwandte von frontalis auf Sachalin lebt, kann man von einer Einwanderung aus nördlicher Richtung ausgehen.

Tachyporus abdominalis ist holarktisch verbreitet und erreicht in Japan die südliche Grenze seiner Verbreitung. Die Art ist zweifellos von Norden nach Japan eingewandert.

Die Verwandtschaftsbeziehungen von Tachyporus suavis sind zur Zeit noch nicht geklärt. Die Art ist von Kyushu bis in den nördlichen Teil Honshus verbreitet.

\subsection{Sachalin}

Über die Staphylinidenfauna Sachalins liegen bis heute keine Übersichten vor. Auch den Revisoren ostpaläarktischer Staphylinidentaxa lagen meist nur Einzelstücke zur Revision vor. Das Vorkommen zahlreicher endemischer Tachyporus-Arten auf Sachalin wäre für Arten niederer Lagen des Arboreals überraschend. ZERCHE (mündl. Mitt.) nennt neben endemischen Coryphiinen jedoch auch endemische Arten der Omaliinengattungen Mannerheimia und Olophrum. 


\begin{tabular}{|l|l|c|c|}
\hline \multicolumn{1}{|c|}{ Taxon } & \multicolumn{1}{|c|}{ Autoren } & Sachalin & Endemisch \\
\hline Tachinus & $\begin{array}{l}\text { ULLRICH (1975), LI (1984, 1985a, } \\
\text { 1985b), VESELOVA (1990) }\end{array}$ & 5 & 1 \\
\hline Megarthrus & $\begin{array}{l}\text { CUCCODORO (1996), CUCCODORO \& } \\
\text { LöBL (1997) }\end{array}$ & 1 & 0 \\
\hline Silphidae & LAFER (1989) & 13 & 0 \\
\hline Coryphiini & $\begin{array}{l}\text { ZERCHE (1990, 1993 + unveröffent- } \\
\text { lichte Daten) }\end{array}$ & 4 & 3 \\
\hline Tachyporus & \multicolumn{1}{|l}{} & 7 & 1 \\
\hline
\end{tabular}

Tab. 21: Vergleich der Endemitenrate verschiedener Taxa der Staphylinoidea auf Sachalin.

Die auf Sachalin lebenden Tachyporus-Arten gehören der chrysomelinus-Gruppe (wrasei, chrysomelinus, sp. cf. pulchellus), der abdominalis-Gruppe (abdominalis) und zur Verwandtschaft von obtusus und solutus (puetzi, terminalis) bzw. von obscurellus (sp. cf. obscurellus). Bei allen Arten ist davon auszugehen, daß sie selbst oder ihre Vorfahren von Norden her nach Sachalin eingewandert sind. Wahrscheinlich sind die beiden hier von Sachalin beschriebenen Arten weiter verbreitet und auch auf Hokkaido bzw. dem ostasiatischen Festland zu finden, so wurde Tachyporus puetzi, der aus zahlreichem Material aus dem Fernen Osten Rußlands nicht vorliegt, in einem Einzelstück aus dem Baikalgebiet nachgewiesen.

\subsection{Schlußfolgerungen}

Für die meisten auf Sachalin und dem Japanischen Archipel vorkommenden Tachyporus läßt sich eine geographische Herkunft wahrscheinlich machen, dies gilt nicht für den Zeitpunkt der Einwanderung der Arten oder ihrer Vorfahren in das Untersuchungsgebiet. Aus der Gegenüberstellung der hier gewonnenen Untersuchungsergebnisse lassen sich folgende Hypothesen aufstellen: Die Tachyporus-Fauna Japans und Sachalins ist wahrscheinlich auf zwei unterschiedlichen Wegen in das Gebiet eingewandert. Arten der atriceps-Gruppe sind aus südlicher Richtung nach Japan eingewandert, ihr Vorkommen erreicht nach Norden die Mitte der Insel Honshu. Als Einwanderungsweg ist eine Verbindung über die Straße von Tsushima die wahrscheinlichste Hypothese. Eine solche Landbrücke wird auch von KRIVOLUTZKAYA (1973) angenommen, eine Besiedlung Japans durch die Vorfahren von Epaphiopsis, Trichiama und Agonotrechus (Carabidae: Trechinae) aus südlicher Richtung auch von UENO (1992). Da für das letzte Glazial die eustatische Absenkung des Meeresspiegels um weniger als $100 \mathrm{~m}$ für ein völliges Trockenfallen der Straße von Tsushima nicht ausreicht, könnte das ein Hinweis auf die Einwanderung der betreffenden Arten bereits zu früherer Zeit sein. Die Vorfahren der meisten anderen Arten sind aus nördlicher Richtung nach Sachalin eingewandert bzw. über Sachalin nach Japan gelangt. Die Herkunft von Tachyporus suavis SHARP bleibt fraglich. Im Vergleich zu anderen untersuchten Staphylinidentaxa ist der Anteil endemischer Arten in Japan etwa gleich groß. Der Vergleich mit den oft in ähnlichen Lebensräumen vorkommenden Arten der Gattung Tachinus zeigt, daß die meisten Tachinus-Arten weiter über Japan verbreitet sind, nur $40 \%$ der Arten sind nach bisherigen Kenntnissen als Inselendemiten anzusehen. Daß nur $36 \%$ der aus Japan bekannten Tachyporus von mehr als einer der Hauptinseln bekannt sind, liegt wohl eher an der geringen Mate- 
rialbasis, da die meisten Arten flugfähig sind und somit weiter verbreitet sein sollten. Besonders unzureichend ist die Materialbasis von Hokkaido, wo mit dem Vorkommen der hier von Sachalin beschriebenen Arten zu rechnen ist.

Mit dem Vorkommen weiterer Arten in Japan (sowohl neuer als auch weiterer kontinentaler Arten) ist zu rechnen. In der Literatur wurden Tachyporus atriceps, pusillus und chrysomelinus aus Japan gemeldet. Die beiden erstgenannten Arten erreichen in ihrer östlichen Ausbreitung nach bisheriger Kenntnis den östlichen Teil der Paläarktis nicht, beide Meldungen dürften auf Verwechslungen mit anderen Arten beruhen. Die Verbreitung von Tachyporus chrysomelinus in Ostasien ist Gegenstand weiterer Untersuchungen. Die Art könnte aber zumindest im nördlichen Teil Japans vorkommen. Die bisherigen Meldungen können aber auch auf Verwechslungen mit dem hier beschriebenen Tachyporus celatoides beruhen.

\section{Literatur}

Bernhauer, M. \& SChuberT, K. 1916: Coleopterorum Catalogus Pars 67, Staphylinidae V, Berlin, p. 409-498.

BERNHAUER, M. 1917: Neue Staphyliniden der palearktischen Fauna nebst synonymischen Bemerkungen. Coleopterologische Rundschau 3, 3-6, 17-23.

BERNHAUER, M. 1927: Neue Staphyliniden des paläarktischen Faunengebietes. - Koleopterologische Rundschau 13, 2-3, 90-99.

BERNHAUER, M. 1938: Neuheiten der Staphylinidenfauna der Mandschurei. - Koleopterologische Rundschau 24, 1-2, 20-29.

CAMERon, M. 1933: New Species of Staphylinidae (Col.) from Japan. - Entomologist's Monthly Magazine 69, 168-175.

CAMPBELL, J. M. 1979: A Revision of the Genus Tachyporus GravenHorst (Coleoptera: Staphylinidae) of North and Central America. - Memoirs of the Entomological Society of Canada - No. 109, Ottawa, $3+95$ pp.

CUCCODORO, G. \& LöBL, I. 1997: Revision of the Palearctic rove beetles of the genus Megarthrus CURTIS (Coleoptera: Staphylinidae: Proteininae). - Journal of Natural History 31, 1347-1415.

CUCCODORo, G. 1996: Revision of the Japanese rove-beetles of the genus Megarthrus (Coleoptera, Staphylinidae, Proteininae). - Revue suisse de Zoologie 103, 2, 475-524.

HIRASHIMA, Y. 1989: Coleoptera, Staphylinidae. - In: A Check list of Japanese Insects, I. p. 256-287.

KLOTZ, G. 1989: Die Hochgebirge der Japanischen Inseln. - In: KLOTZ, G.: Hochgebirge der Erde und ihre Pflanzen- und Tierwelt. Leipzig; Jena; Berlin: Urania-Verl., 230-237.

KRIVOLUTZKAYA, G. O. 1973: Entomofauna kurilskych ostrovov. - Leningrad, 1-315.

LAFER, G. SCH. 1989: Silphidae - Mertvojedy i Mogilschtschiki. - In: Opredelitel Nasekomych Dalnevo Vostoka SSSR, 3, 1, p. 329-344.

LI, LI-ZHEN 1994: Two new species of the Genus Tachinus (Coleoptera, Staphylinidae) from the Ryukyu Islands, Southwest Japan. - Japanese Journal of Entomology 62, 4, 661-666.

LI, LI-ZHEN 1995a: A Revision of the Genus Tachinus GRAVENHORST (Coleoptera, Staphylinidae) of Japan, II. - Japanese Journal of Systematic Entomology 1, 1, 51-72.

LI, LI-ZHEN 1995b: A Revision of the Genus Tachinus GravenHorsT (Coleoptera, Staphylinidae) of Japan, II. - Japanese Journal of Systematic Entomology 1, 2, 201-216.

LUZE, G. 1901: Revision der europäischen und sibirischen Arten der Staphyliniden-Gattungen Tachyporus GRAV. und Lamprinus HEER. - Verhandlungen der Zoologisch-botanischen Gesellschaft Wien 51, 146-185.

SCHEERPELTZ, O. 1934: Coleopterorum Catalogus Pars 130, Staphylinidae VIII, Berlin, p. 1500-1881.

SCHÜLKE, M. 1991: Studien zur Systematik und Faunistik der Gattung Tachyporus GrAV. (Coleoptera, Staphylinidae). - Entomologische Nachrichten und Berichte 35, 1, 5-16.

SCHÜLKE, M. 1995a: Tachyporinenfunde aus Ost-Sibirien (Coleoptera: Staphylinidae). - Koleopterologische Rundschau 65, 27-41. 
SCHÜLKE, M. 1995b: Studien zur Systematik und Faunistik der Gattung Tachyporus GravenHORST (Coleoptera, Staphylinidae, Tachyporinae), Teil 3. - Entomologische Nachrichten und Berichte 39, 1-2, 81-89.

SCHÜLKE, M. 1995c: Tachyporus lohsei spec. nov., die erste Art der Gattung vom südchinesischen Festland (Coleoptera, Staphylinidae). - Entomologische Blätter 91, 3, 142-148.

SCHÜLKE, M. 1996: Studien zur Systematik und Faunistik der Gattung Tachyporus GravenhoRsT (Coleoptera: Staphylinidae), Teil 4: Tachyporus vafer spec. nov., eine neue Art aus Mitteleuropa. Linzer biologische Beiträge 28, 1, 483-495.

SCHÜLKE, M. 1997: Studien zur Systematik und Faunistik der Gattung Tachyporus GRAVENHORST, Teil 5: Zur Kenntnis der westpaläarktischen Arten der Tachyporus atriceps STEPHENS, 1832-Gruppe (Coleoptera; Staphylinidae). - Koleopterologische Rundschau 67, 131-158.

SHARP, D. 1874: The Staphylinidae of Japan. - Transactions of the Entomological Society of London 1874, 1, 1-103.

SHARP, D. 1888: The Staphylinidae of Japan. - Annals and Magazin of Natural History, London, Ser. 6, 2, 451-464.

SHibATA, Y. 1991: Three New Gabrius (Coleoptera, Staphylinidae) from Japan. - Elytra 19, 1, 85-92.

SmetanA, A. 1984a: Review of the Japanese Species of the Genus Gabrius STEPHENs (Coleoptera, Staphylinidae). - Pan-Pacific Entomologist 60, 2, 122-150.

SMETANA, A. 1984b: A new species of the genus Gabrius STEPHENS from Japan (Coleoptera, Staphylinidae). - Revue suisse de Zoologie 91, 3, 647-650.

Ueno, S.-I. 1992: Differences in the Trechine Faunas of the Philippines and Taiwan (Coleoptera: Carabidae). - In: NoONAN, G. R.; BALL, G. E. \& STORK, N. E.: Biogeography of Ground Beetles of Mountains and Islands, p. 187-199.

Uhlig, M. \& WATANABE, Y. 1992: Revision of the Japanese Species of the Genus Erichsonius FaUveL (Coleoptera, Staphylinidae, Philonthini). - Mitteilungen aus dem Zoologischen Museum Berlin 68, 1, 3-92.

UlLRICH, W. G. 1975: Monographie der Gattung Tachinus GravenHORST (Coleoptera: Staphylinidae) mit Bemerkungen zur Phylogenie und Verbreitung der Arten. - Kiel, 1-365, 61 tab.

Veselova, E. M. 1990: Novye widy Tachinus (Coleoptera, Staphylinidae) fauny SSSR. - Vestnik zoologii 1990, 3, 13-16.

ZERCHE, L. 1990: Monographie der paläarktischen Coryphiini (Coleoptera, Staphylinidae, Omaliinae). AdL, Berlin, 1-413.

ZERCHE, L. 1993: Monographie der paläarktischen Coryphiini (Coleoptera, Staphylinidae, Omaliinae). Supplementum 1. - Beiträge zur Entomologie 43, 2, 319-374.

Anschrift des Verfassers:

MICHAEL SCHÜLKE

Rue Ambroise Paré 11

mschuelke.berlin@t-online.de

D- 13405 Berlin

Deutschland 